\title{
Small-Signal Modeling and Controller Design of Energy Sharing Controlled Distributed Battery System
}

Wangxin Huang and Jaber A. Abu Qahouq

\begin{abstract}
This paper presents small-signal modeling, analysis and closed-loop controller design guidelines for a distributed battery energy storage system with energy sharing controller which has recently been presented in the literature in order to achieve cell balancing with high cell balancing speed and energy efficiency. The derived small signal models provide deeper insight into the dynamics of the energy sharing controlled battery system under different operating modes, including discharge mode, constant current charging mode and constant voltage charging mode. Based on the derived small signal models, closed-loop controller design guidelines are provided based on rule-of-thumb frequency-domain design criteria. The small signal models and designed controllers are validated by MATLAB®/SIMULINK simulation and experimental prototype results.
\end{abstract}

Keywords: Small-Signal Modeling; Distributed Battery System; Cell Balancing; Energy-Sharing Control; Controller Design; Battery Power Module.

\section{Introduction}

Batteries and battery systems are widely used in many applications including portable electronics, EVs/HEVs, and distributed smart power grids [1-6]. In addition to battery 
technologies, the battery management system (BMS) plays a critical role in enabling the widespread adoption of battery-powered applications [7-11].

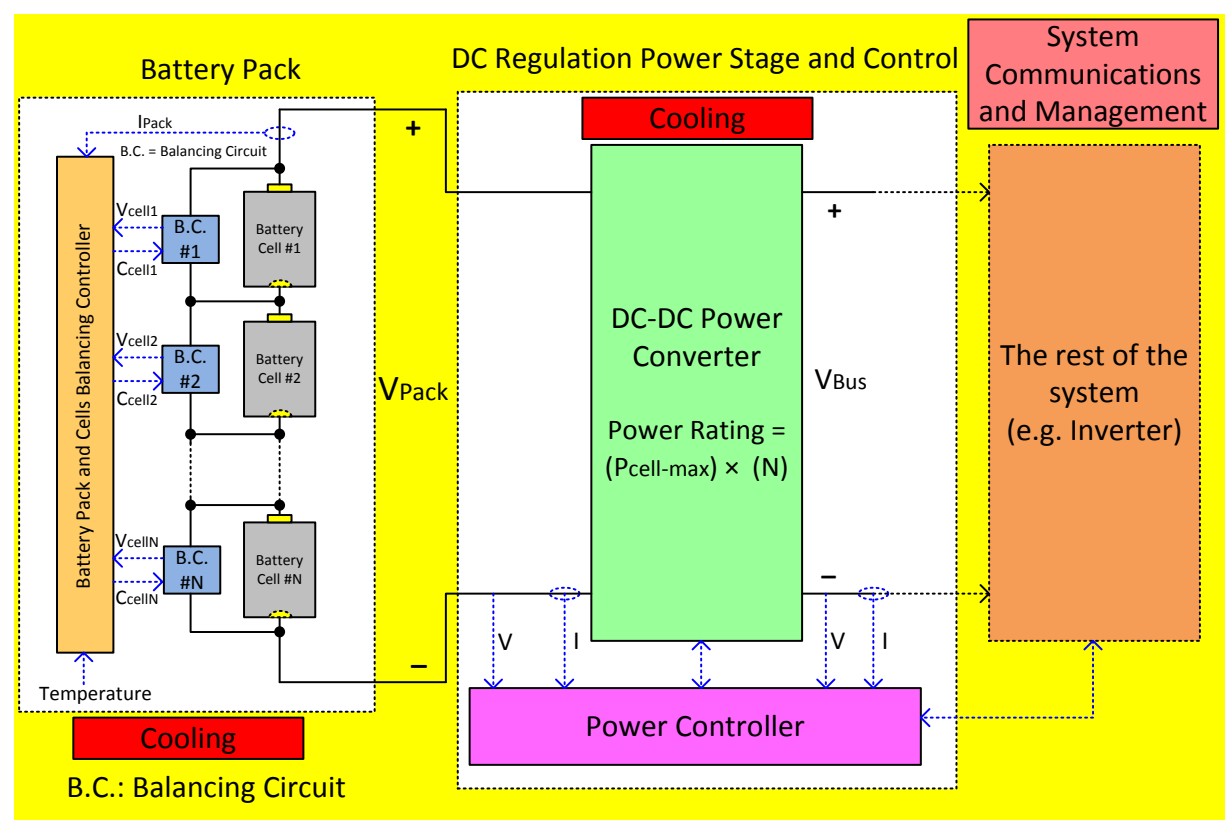

(a)



(b)

Fig. 1. A simplified block diagram of (a) a conventional centralized battery system architecture and (b) distributed battery system architecture with energy sharing control [1]. 
A conventional battery system architecture is shown below in Fig. 1(a). A battery pack, which consists of a number of cells that are connected in series, is connected to the load through a single high-power converter. In this centralized architecture, additional cell balancing circuitries and controllers are needed in order to achieve the cell balancing between the battery cells in the battery pack. In other words, while the bus voltage regulation is achieved by using a single power converter with its own independent controller, the cell balancing functionality is independently achieved by using another controller that control several balancing circuits across the individual battery cells.

On the other hand, an energy sharing controller has been presented in [1] which achieves cell balancing for a distributed battery system with high cell balancing speed and energy efficiency during both discharging and charging operation. As shown in Fig. 1(b), unlike the conventional system of Fig. 1(a), the distributed battery system consists of a number of battery power modules (BPMs) connected in series in order to supply higher power to the load. Each BPM is made up of a battery cell and a small low-power DC-DC power converter. The selection of the BPM converter topology is a function of several factors including power density, efficiency, cost and size, among others [13-19]. In this work, a bidirectional boost/buck topology is used for BPM converter. The converter operates in boost mode during discharging operation while operating in buck mode during charging operation. The steady-state operation and analysis of the energy sharing controller has been presented in [1].

The energy-sharing based distributed battery architecture addresses the cell balancing and the bus voltage and cell voltage/current regulation of the battery system simultaneously with the same converter system. Therefore, the cell balancing, bus voltage and cell voltage/current control loops are coupled with each other. In addition, the control loops of each battery power module 
also interact with one each other. This coupling and interaction nature and the use of the energy sharing control presented in [1] make it important to develop the small-signal modeling analysis in order to understand the dynamics and stability of the entire distributed battery system as well as provide insights into the design and optimization of the multiple control loops involved. This is the main objective of this paper.

Detailed small-signal modeling and analysis is performed in this paper for each operating mode, i.e., discharge mode, constant current charging mode and constant voltage charging mode. In each mode, the corresponding small signal model of the system is first constructed, followed by derivation of associated transfer functions. Finally, the control loops including BPM voltage, SOC balancing, average cell current and average cell voltage loops are compensated based on rule-of-thumb frequency-domain design guidelines and criteria, i.e., control bandwidth and stability margins.

Several different small-signal modeling techniques are introduced and discussed in [20], including basic AC modeling, state-space averaging, circuit averaging techniques. In this paper, the state-space averaging method is employed to derive the small-signal models and associated transfer functions.

Section 2 to Section 5 presents the small-signal modeling analysis, transfer functions derivation in addition to the closed-loop compensators' design for various operating modes. Simulation model and proof-of-concept experimental prototype results are presented and discussed in Section 6 in order to validate the derived small signal models and controllers design. Conclusion is given in Section 7. 


\section{Energy Sharing Controller Modeling and Design For Discharge Operation}

\subsection{Small-Signal Model}

Energy sharing controller presented in [1] consists of two closed control loops in battery discharge mode, i.e., BPM output voltage control loop and SOC balancing control loop. The basic control block diagrams of the energy sharing controlled distributed battery system in discharge mode are shown in Fig. 2, where $\mathrm{V}_{\text {bus-ref }}$ is the reference value of the DC bus voltage. $\alpha_{\mathrm{v} 1} \ldots \alpha_{\mathrm{vN}}$ are the voltage loop multipliers; $\mathrm{M}_{\mathrm{v}}$ is the sum of the voltage loop multipliers; $\mathrm{SOC}_{1} \ldots \mathrm{SOC}_{\mathrm{N}}$ are the $\mathrm{SOC}$ values of the cells; $\mathrm{SOC}_{\mathrm{ref}}$ is the reference $\mathrm{SOC}$ value; $\mathrm{D}_{1} \ldots \mathrm{D}_{\mathrm{N}}$ are the duty cycle values of the converters in the BPMs; $\mathrm{G}_{\mathrm{vr}-\mathrm{dhg}}$ and $\mathrm{G}_{\mathrm{socr}-\mathrm{dhg}}(\mathrm{r}=1,2, \ldots \mathrm{N})$ are the transfer functions of the compensators for the BPM output voltage and SOC balancing control loop, respectively. The SOC balancing control loop is used to achieve SOC balancing between the battery cells by adjusting the voltage multipliers $a_{\mathrm{v} 1}$ through $a_{\mathrm{vN}}$ which in turn change the discharge rate of each cell. The BPM output voltage control loop is used to regulate the output voltage of each BPM, i.e., $\mathrm{V}_{1}$ through $\mathrm{V}_{\mathrm{N}}$.

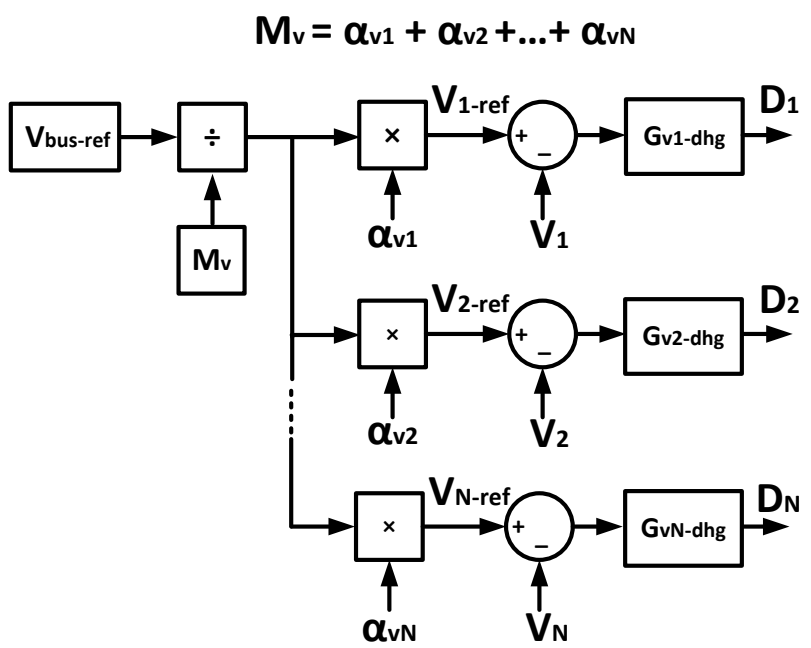

(a)

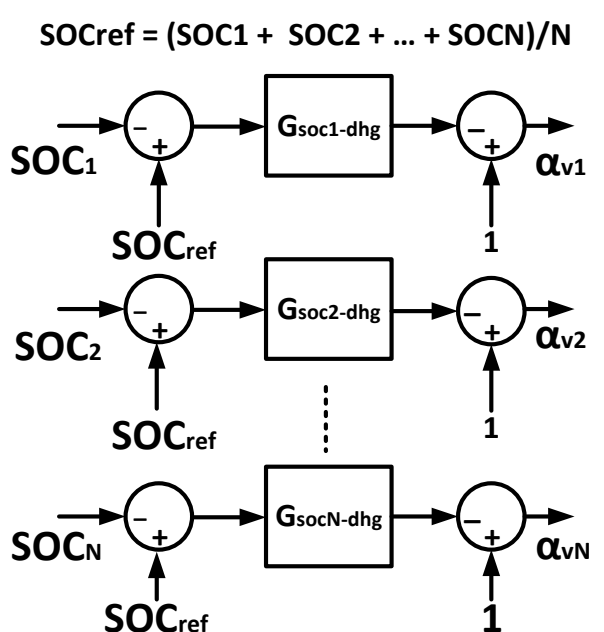

(b)

Fig. 2. The energy sharing controller's basic block diagram during discharging operation: (a) the BPM output voltage control loop and (b) SOC balancing control loop [1]. 
The voltage loop multipliers $\alpha_{\mathrm{v} 1} \ldots \alpha_{\mathrm{vN}}$ are adjusted by the SOC balancing control loops according to the SOC values of the cells. If a cell has a higher SOC value than the other cells, its voltage loop multiplier value will be set greater than that of the other cells. The voltage loop multiplier values are then used in the voltage control loops to result in different output voltage values for the BPMs. Since the output current is the same for all the BPMs, these different output voltages will lead to different discharge rates of the cells. As a result, the cell that has higher SOC value will be discharged faster than the other cells in order to achieve cell balancing between the cells. Meanwhile, the bus voltage $\mathrm{V}_{\text {bus }}$ is regulated at $\mathrm{V}_{\text {Bus-ref. }}$ The detailed operation of the energy sharing controller can be found in [1].

Based on two basic control block diagrams shown in Fig. 2, the small-signal model for the energy sharing controlled distributed battery system during discharging operation can be derived as shown in Fig. 3. Note that all the variables shown in Fig. 3 are AC small signal variations. The transfer functions and symbols shown in Fig. 3 are described below. All the following transfer functions are for discharging operation unless otherwise noted. For generalization, all the transfer function are for $\mathrm{r}^{\text {th }}$ BPM.

$T_{v r-d h g}(s)$ : BPM output voltage control loop gain;

$T_{\text {socr-dhg }}(s)$ : SOC balancing control loop gain;

$G_{v d r-d h g}(s)$ : duty cycle control to BPM output voltage transfer function;

$G_{i d r-d h g}(s):$ duty cycle control to cell current transfer function;

$Z_{\text {or }}(s):$ BPM open loop output impedance transfer function;

$G_{\text {socir-dhg }}(s)$ : cell current to cell SOC transfer function;

$G_{v r-d h g}(z)$ : BPM output voltage control loop compensator; 

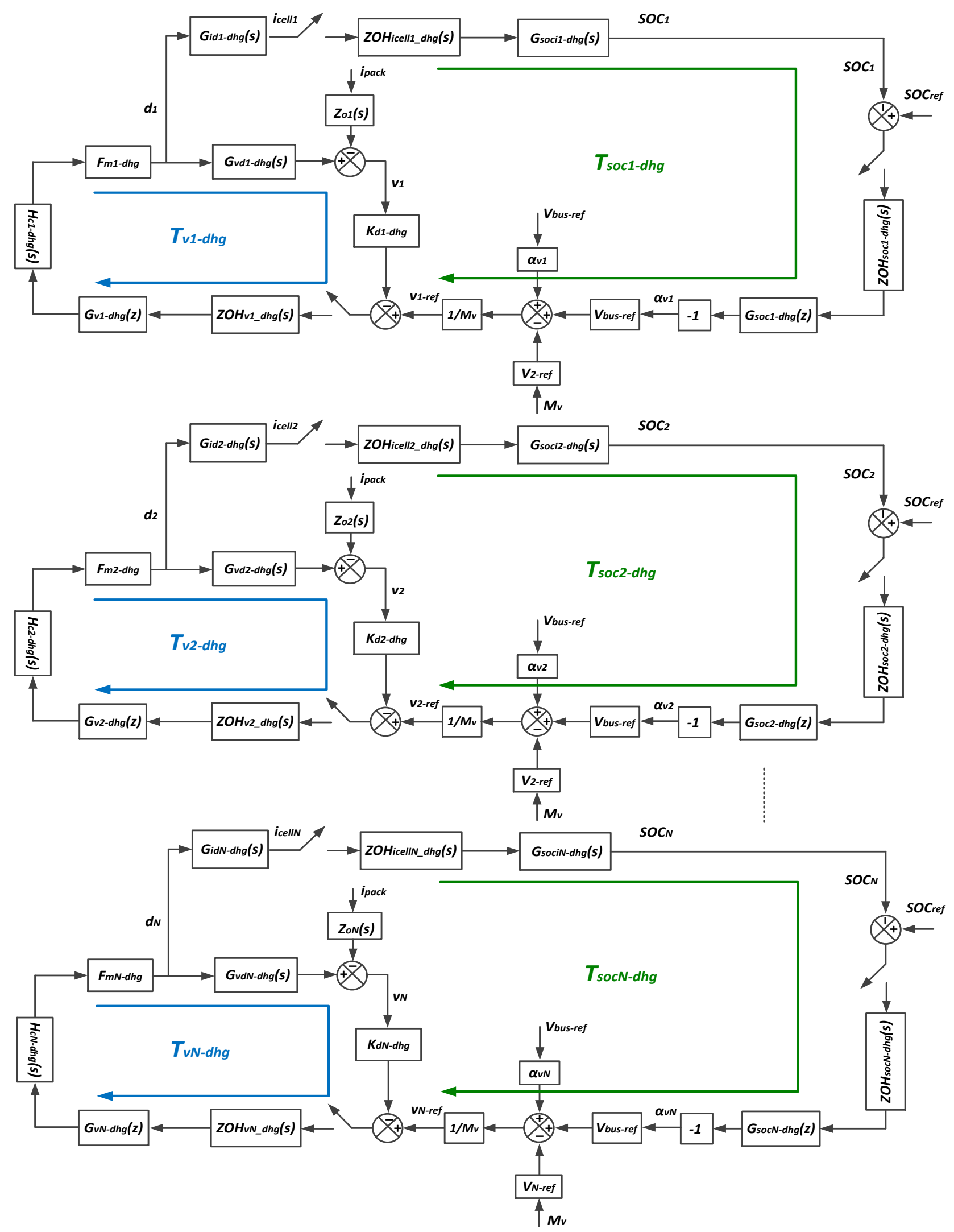

Fig. 3: Small-signal model of the energy sharing controlled distributed battery system in discharge mode. 
$G_{\text {socr-dhg }}(z)$ : SOC balancing control loop compensator;

$K_{d r-d h g}(s)$ : BPM output voltage sensing gain (including the voltage sensor gain and the analog-to-digital converter gain);

$F_{m r-d h g}(s)$ : PWM modulator gain;

$H_{c r-d h g}(s)$ : digital controller computation delay model;

$Z O H_{v r-d h g}(s):$ zero order hold model for BPM output voltage sampling;

$Z O H_{\text {icellr-dhg }}(s)$ : zero order hold model for cell current sampling;

$Z O H_{\text {socr-dhg }}(s)$ : zero order hold model for cell SOC sampling;

The converter design parameters and equilibrium operating point (when the battery cells are balanced) are the same for all the BPMs. Therefore, the compensators design for all the BPMs are identical. The following section presents the derivation of the transfer functions for $\mathrm{r}^{\text {th }}$ BPM during discharging operation.

\subsection{Derivation of Transfer Functions}

In discharge mode, the BPM converters operate in boost mode with the battery cells being the inputs as shown in Fig. 4. The independent state variables of a BPM converter in this mode are the inductor current or cell current $i_{\text {cell }}(t)$ and the BPM converter output voltage $v(t)$. The input variables are cell open circuit voltage $V_{o c}(t)$ and output current or battery pack current $\mathrm{i}_{\text {pack }}(\mathrm{t})$. The output variables are the same as the state variables.

The state equations for $\mathrm{r}^{\text {th }}$ BPM during each subinterval are derived from Fig. 4. When $\mathrm{S}_{\mathrm{lr}}$ is on and $\mathrm{S}_{\mathrm{ur}}$ is off during $\mathrm{d}_{\mathrm{r}} \mathrm{T}_{\mathrm{sw}}$ time duration, the state equations are

$$
\left\{\begin{array}{c}
L \frac{d i_{\text {cell } r}(t)}{d t}=v_{o c r}(t)-i_{\text {cellr }}(t) \cdot Z_{\text {cellr }} \\
C \frac{d v_{r}(t)}{d t}=-i_{\text {pack }}(t)
\end{array}\right.
$$


where $d_{r}$ is the duty cycle and $T_{s w}$ is the switching period of the BPM converter. Other variables are as defined in Fig. 4. When $S_{\mathrm{ur}}$ is on and $\mathrm{S}_{\mathrm{lr}}$ is off during $\left(1-\mathrm{d}_{\mathrm{r}}\right) \cdot \mathrm{T}_{\mathrm{sw}}$ time duration, the state equation is given by

$$
\left\{\begin{array}{c}
L \frac{d i_{c e l l r}(t)}{d t}=v_{o c r}(t)-i_{c e l l r}(t) \cdot Z_{c e l l r}-v_{r}(t) \\
C \frac{d v_{r}(t)}{d t}=i_{c e l l r}(t)-i_{p a c k}(t)
\end{array}\right.
$$

Equations (1) and (2) can be rewritten in the following state-space form:

$$
\begin{aligned}
& K \frac{d x(t)}{d t}=A_{1} x(t)+B_{1} u(t) \\
& K \frac{d x(t)}{d t}=A_{2} x(t)+B_{2} u(t)
\end{aligned}
$$

Where $K=\left[\begin{array}{ll}L & 0 \\ 0 & C\end{array}\right], A 1=\left[\begin{array}{cc}-Z_{\text {cellr }} & 0 \\ 0 & 0\end{array}\right], B 1=\left[\begin{array}{cc}1 & 0 \\ 0 & -1\end{array}\right], A 2=\left[\begin{array}{cc}-Z_{\text {cellr }} & -1 \\ 1 & 0\end{array}\right], B 2=$

$$
\left[\begin{array}{cc}
1 & 0 \\
0 & -1
\end{array}\right], x(t)=\left[\frac{i_{c e l l r}(t)}{v_{r}(t)}\right], \text { and } u(t)=\left[\frac{v_{o c r}(t)}{i_{\text {pack }}(t)}\right]
$$

The next step is to evaluate the state-space averaged equilibrium equations. The averaged matrix $\mathrm{A}$ is

$$
A=D_{r} A 1+D_{r}{ }^{\prime} A 2=D_{r}\left[\begin{array}{cc}
-Z_{\text {cellr }} & 0 \\
0 & 0
\end{array}\right]+D_{r}{ }^{\prime}\left[\begin{array}{cc}
-Z_{\text {cellr }} & -1 \\
1 & 0
\end{array}\right]=\left[\begin{array}{cc}
-Z_{\text {cellr }} & -D_{r}{ }^{\prime} \\
D_{r}{ }^{\prime} & 0
\end{array}\right]
$$

where $D_{r}$ is the value of $d_{r}$ at the equilibrium operating point, and $D_{r}^{\prime}=1-D_{r}$.

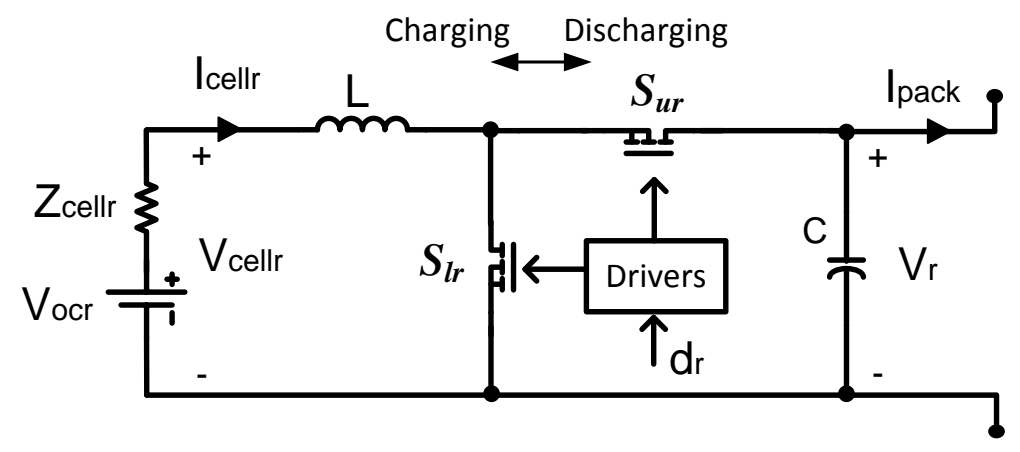

Fig. 4: Circuit diagram of a BPM

Similarly, the averaged matrix B is 
$B=D_{r} B 1+D_{r}{ }^{\prime} B 2=D_{r}\left[\begin{array}{cc}1 & 0 \\ 0 & -1\end{array}\right]+D_{r}{ }^{\prime}\left[\begin{array}{cc}1 & 0 \\ 0 & -1\end{array}\right]=\left[\begin{array}{cc}1 & 0 \\ 0 & -1\end{array}\right]$

Then the equilibrium state vector $\mathrm{X}$ is

$X=-A^{-1} B U=-\left[\begin{array}{cc}-Z_{c e l l r} & -D_{r}^{\prime} \\ D_{r}{ }^{\prime} & 0\end{array}\right]^{-1}\left[\begin{array}{cc}1 & 0 \\ 0 & -1\end{array}\right]\left[\begin{array}{c}V_{o c r} \\ I_{\text {pack }}\end{array}\right]=\frac{1}{D_{r}{ }^{\prime 2}}\left[\begin{array}{c}D_{r}{ }^{\prime} I_{\text {pack }} \\ D_{r}{ }^{\prime} V_{o c r}-Z_{\text {cellr }} I_{\text {pack }}\end{array}\right]$

For the distributed battery system design presented in [1], the equilibrium (DC) operating point parameters are listed in Table 1 and the BPM power stage parameters are given in Table 2. The vector coefficient of $\widehat{d_{r}(t)}$ is

$$
(A 1-A 2) X+(B 1-B 2) U=\left[\begin{array}{cc}
0 & 1 \\
-1 & 0
\end{array}\right] X+\left[\begin{array}{ll}
0 & 0 \\
0 & 0
\end{array}\right]\left[\begin{array}{c}
V_{o c r} \\
I_{\text {pack }}
\end{array}\right]=\frac{1}{D_{r}{ }^{2}}\left[\begin{array}{c}
D_{r}{ }^{\prime} V_{o c r}-Z_{c e l l r} I_{\text {pack }} \\
-D_{r}{ }^{\prime} I_{\text {pack }}
\end{array}\right]
$$

where $\widehat{d_{r}(t)}$ is the small signal variation of $d_{r}(t)$ around its equilibrium operating point $D_{r}$.

Table 1

Equilibrium (DC) Operating Point Parameter Values in Discharge Mode

\begin{tabular}{ll}
\hline Parameter & Value \\
\hline$V_{\text {cellr }}$ & $3.7 \mathrm{~V}$ \\
$V_{r}$ & $8 \mathrm{~V}$ \\
$V_{\text {bus-ref }}$ & $16 \mathrm{~V}$ \\
$M_{v}$ & 2 \\
$\alpha_{v l}=\alpha_{v 2}$ & 1 \\
$Z_{\text {cellr }}$ & $65 \mathrm{~m} \Omega$ \\
$I_{\text {pack }}$ & $0.65 \mathrm{~A}$ \\
$D_{r}$ & 0.5492 \\
$D_{r}{ }^{\prime}$ & 0.4508 \\
\hline
\end{tabular}

Table 2

Main BPM Design Parameters

\begin{tabular}{ll}
\hline Parameter & Value \\
\hline$V_{\text {in }}=V_{\text {cell }}$ & $3 \mathrm{~V}-4.2 \mathrm{~V}$ \\
$V_{r}$ & $6 \mathrm{~V}-10 \mathrm{~V}$ \\
$L$ & $100 \mu \mathrm{H}$ \\
$C_{o}$ & $220 \mu \mathrm{F}$ \\
$f_{s w}$ & $150 \mathrm{kHz}$ \\
$I_{\text {pack }}($ nominal $)$ & $0.65 \mathrm{~A}$ \\
$Q($ rated $)$ & $2.6 \mathrm{Ah}$ \\
\hline
\end{tabular}


The small-signal AC state equations therefore become

$\left[\begin{array}{ll}L & 0 \\ 0 & C\end{array}\right] \frac{d}{d t}\left[\begin{array}{c}l_{\text {cellr }}(t) \\ v_{r}(t)\end{array}\right]=\left[\begin{array}{cc}-Z_{\text {cellr }} & -D_{r}^{\prime} \\ D_{r}^{\prime} & 0\end{array}\right]\left[\begin{array}{c}l_{\text {cellr }}(t) \\ \widehat{v_{r}(t)}\end{array}\right]$

$+\left[\begin{array}{cc}1 & 0 \\ 0 & -1\end{array}\right]\left[\begin{array}{c}\widehat{v_{\text {ocr }}(t)} \\ l_{\text {pack }}(t)\end{array}\right]+\frac{1}{D_{r^{\prime}}{ }^{2}}\left[\begin{array}{c}D_{r}{ }^{\prime} V_{\text {ocr }}-Z_{\text {cellr }} I_{\text {pack }} \\ -D_{r}^{\prime} I_{\text {pack }}\end{array}\right] \widehat{d(t)}$

When written in scalar from, (9) becomes

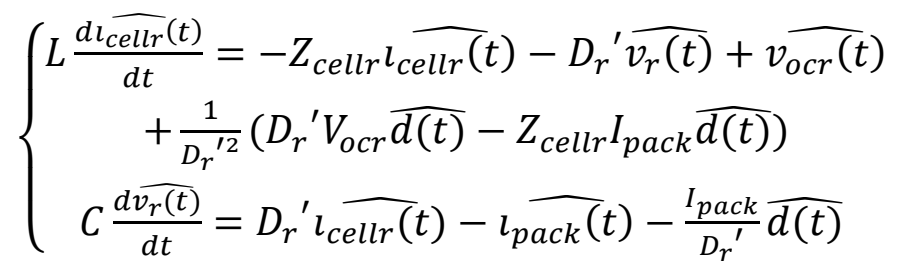

Since the dynamics of the cell open circuit voltage variation $\widehat{v_{\text {ocr }}(t)}$ is very slow compared to the dynamics of the BPM converter, it can be assumed that the AC small signal variation of the cell open circuit voltage around its equilibrium point is 0 , i.e., $\widehat{v_{\text {ocr }}(t)}=0$. Based on this, performing Laplace Transformation on (10) yields

$$
\left\{\begin{array}{c}
s L i_{\text {cellr }}(s)=-Z_{\text {cellr }} i_{\text {cellr }}(s)-D_{r}{ }^{\prime} v_{r}(s)+\frac{1}{D_{r}{ }^{\prime 2}}\left(D_{r}{ }^{\prime} V_{\text {ocr }} d_{r}(s)\right. \\
\left.-Z_{\text {cellr }} I_{\text {pack }} d_{r}(s)\right) \\
s C v_{r}(s)=D_{r}{ }^{\prime} i_{\text {cellr }}(s)-i_{\text {pack }}(s)-\frac{1}{D_{r}{ }^{\prime}} I_{\text {pack }} d_{r}(s)
\end{array}\right.
$$

where $s$ is the Laplace Transform operator $(s=j \omega)$. Let the small signal variation of independent variable $i_{\text {pack }}(s)=0$ and simplify (11) yields

$$
\left\{\begin{array}{c}
s L i_{\text {cellr }}(s)=-Z_{\text {cellr }} i_{\text {cellr }}(s)-D_{r}{ }^{\prime} v_{r}(s)+\frac{1}{D_{r^{\prime}}{ }^{\prime 2}}\left(D_{r}{ }^{\prime} V_{o c r} d_{r}(s)\right. \\
\left.-Z_{\text {cellr }} I_{\text {pack }} d_{r}(s)\right) \\
s C v_{r}(s)=D_{r}{ }^{\prime} i_{c e l l r}(s)-\frac{1}{D_{r}{ }^{\prime}} I_{\text {pack }} d_{r}(s)
\end{array}\right.
$$

Based on (12), the following transfer functions can be derived

$$
G_{v d r-d h g}(s)=\frac{v r(s)}{d r(s)}=\frac{-\left(S L+Z_{\text {cellr }}\right) \frac{I_{\text {pack }}}{D_{r}^{\prime}+\frac{1}{D_{r}{ }^{\prime}}\left(D_{r}{ }^{\prime} V_{o c r}-Z_{\text {cellr }} I_{\text {pack }}\right)}}{\left(S L+Z_{\text {cellr }}\right) S C+D_{r^{\prime}}{ }^{2}}
$$


$G_{i d r-d h g}(s)=\frac{i c e l l r(s)}{d r(s)}=\frac{I_{p a c k}+\frac{1}{D_{r}{ }^{\prime 2}} S C\left(D_{r}{ }^{\prime} V_{o c r}-Z_{\text {cellr }} I_{\text {pack }}\right)}{\left(S L+Z_{\text {cellr }}\right) S C+D_{r}{ }^{2}}$

Likewise, let the AC small signal variation of another independent variable $d_{r}(s)=0$ and simplify (11) yields

$\left\{\begin{array}{c}S L i_{\text {cell }}(s)=-Z_{\text {cellr }} i_{c e l l}(s)-D_{r}{ }^{\prime} v_{r}(s) \\ S C v_{r}(s)=D_{r}{ }^{\prime} i_{c e l l}(s)-i_{\text {pack }}(s)\end{array}\right.$

Based on (15), the following transfer function can be derived,

$Z_{\text {or }}(s)=\frac{v_{r}(s)}{i_{\text {pack }(s)}}=\frac{-\left(S L+Z_{\text {cellr }}\right) \frac{I_{\text {pack }}}{D_{r}{ }^{\prime}}+\frac{1}{D_{r}{ }^{\prime}}\left(D_{r}{ }^{\prime} V_{o c r}-Z_{\text {cellr }} I_{\text {pack }}\right)}{\left(S L+Z_{\text {cellr }}\right) S C+D_{r}{ }^{\prime 2}}$

$G_{\text {socir }-\operatorname{dhg}}(s)=\frac{\operatorname{SOC}_{r}(s)}{i_{\text {cellr }(s)}}=\frac{-T_{s}}{Q}$

where $T_{s}$ is the sampling period of the BPM output voltage, cell current and cell voltage and it is set to be $13.33 \mu$ s (i.e., sampling frequency $=75 \mathrm{kHz}$ ); $Q$ is the rated capacity of the battery cell in coulomb.

\subsection{Compensator Design}

\subsubsection{Voltage Loop Compensator Design}

According to the small-signal model shown in Fig. 3, the discrete-time transfer function of the $\mathrm{r}^{\text {th }}$ BPM converter plant in discharge mode $\mathrm{G}_{\mathrm{pr}-\mathrm{dhg}}(\mathrm{z})$ includes the sampler, $\mathrm{ZOH}$, the BPM output voltage sensing gain $\mathrm{K}_{\mathrm{dr}-\mathrm{dhg}}$, the digital controller computation delay model $\mathrm{H}_{\mathrm{cr}-\mathrm{dhg}}(\mathrm{s})$, in addition to the continuous-time plant $\mathrm{G}_{\mathrm{vdr}-\mathrm{dhg}}(\mathrm{s}) . \mathrm{G}_{\mathrm{pr}-\mathrm{dhg}}(\mathrm{z})$ is given by (18) and its bode plot is represented by the dashed curve in Fig. 5 (a).

$$
\begin{aligned}
& G_{p r-d h g}(z)=Z\left\{Z O H_{v r-d h g}(s) \cdot H_{c r-d h g}(s) \cdot F_{m r-d h g}(s) \cdot G_{v d r-d h g}(s) \cdot K_{d r-d h g}\right\}= \\
& \frac{-0.0002276 \mathrm{z}^{2}-0.0002599 \mathrm{z}+0.0007946}{\mathrm{z}^{3}-1.99 \mathrm{z}^{2}+0.9914 \mathrm{z}}
\end{aligned}
$$

where

$Z O H_{v r-d h g}(s)=\frac{1-e^{-s \cdot T_{s}}}{s}$ 


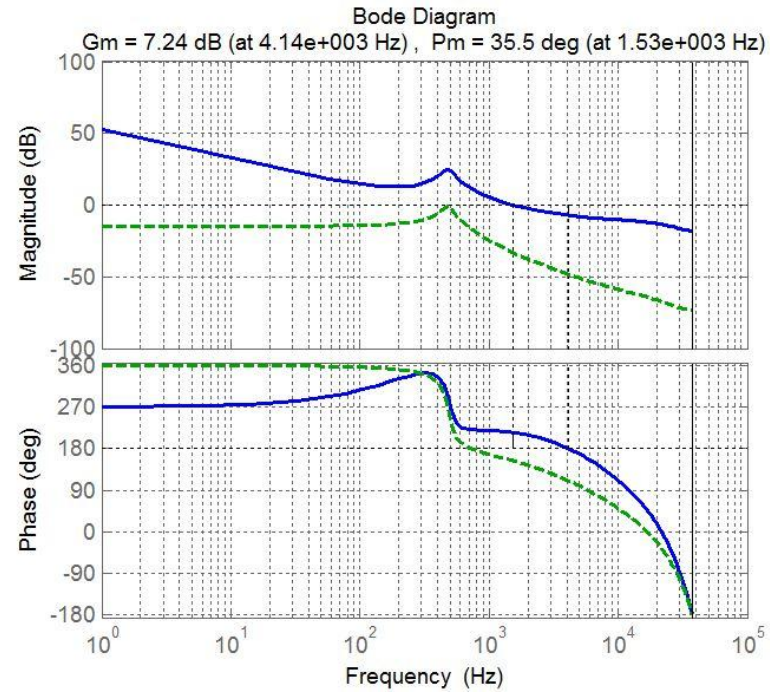

(a)

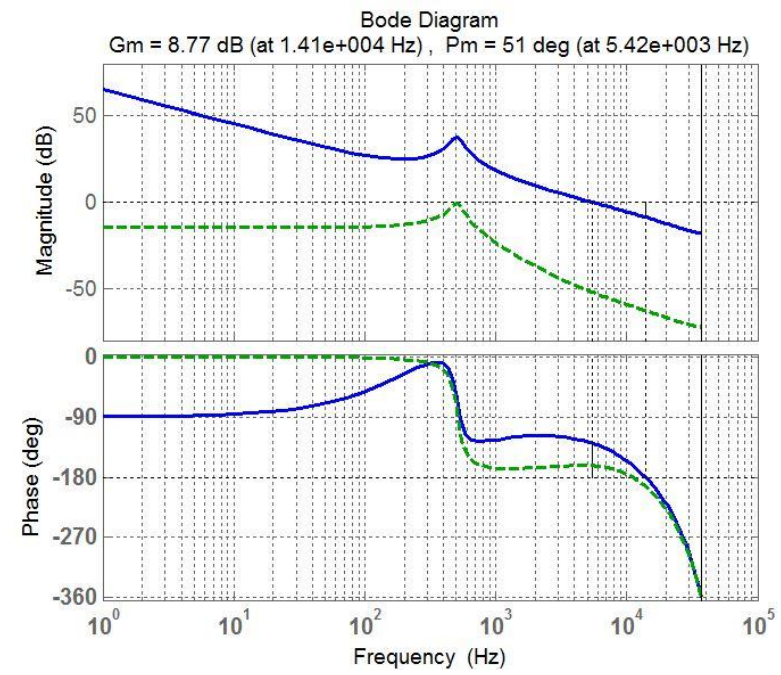

(c)

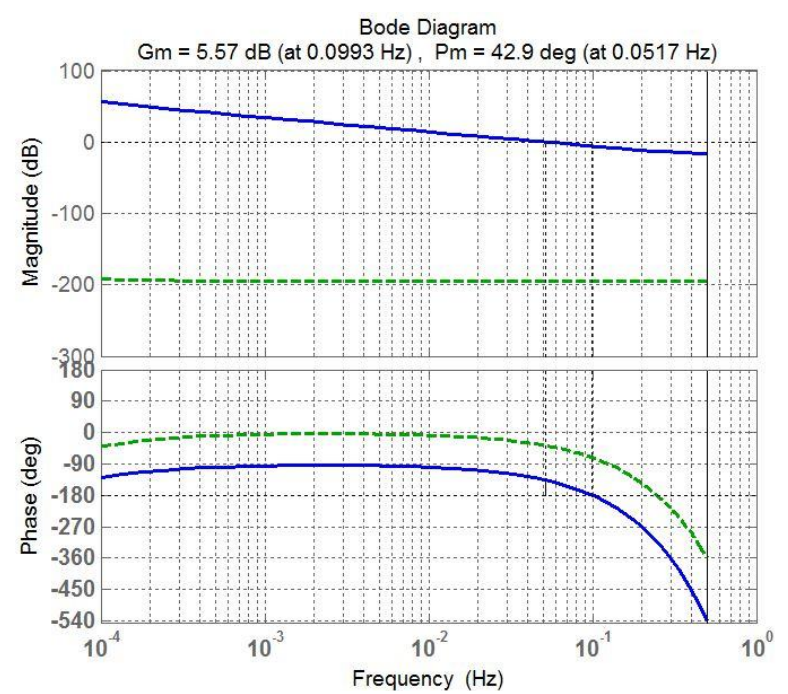

(b)

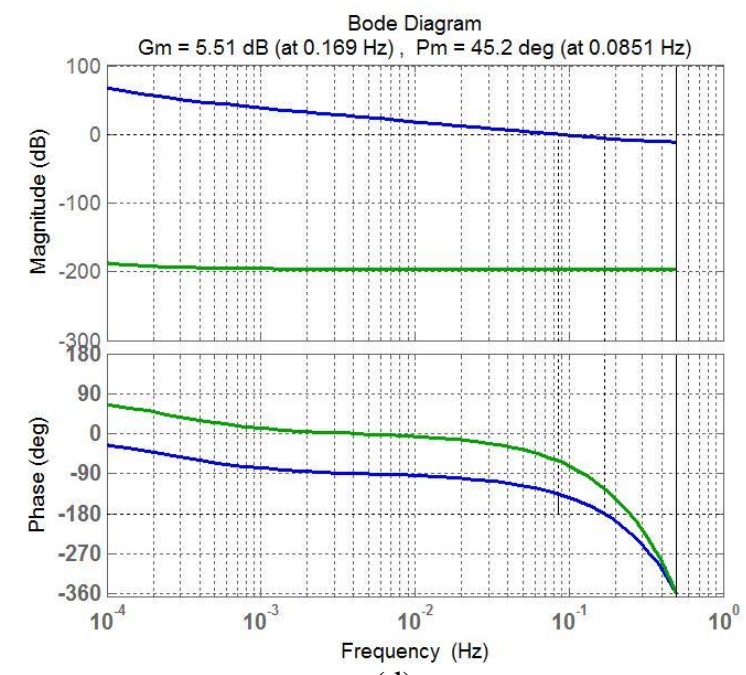

(d)

Fig. 5. The bode plot of the uncompensated (dashed curve) and compensated (solid curve) for (a) BPM output voltage loop gain in discharge mode; (b) SOC balancing loop gain in discharge mode; (c) BPM input voltage loop gain in CCCM; (d) SOC balancing loop gain in CCCM; All at nominal DC operating point.

In this voltage control loop design, the target control bandwidth is limited by the righthalf-plane (RHP) zero located at $3.87 \mathrm{kHz}$, as can be observed from the dashed curve in Fig. 5 
(a). With a compensator $\mathrm{G}_{\mathrm{vr}-\mathrm{dhg}}(\mathrm{z})$ given by (19), the compensated BPM output voltage control loop gain $\left(\mathrm{T}_{\mathrm{vr}-\mathrm{dhg}}(\mathrm{z})=\mathrm{G}_{\mathrm{pr}-\mathrm{dhg}}(\mathrm{z}) \cdot \mathrm{G}_{\mathrm{vr}-\mathrm{dhg}}(\mathrm{z})\right)$ achieves a control bandwidth of $1.53 \mathrm{kHz}$ and a phase margin of $35.5^{\circ}$, as shown on the solid curve in Fig. 5 (a).

$$
G_{v r-d h g}(z)=\frac{0.06059 \mathrm{z}-0.06007}{\mathrm{z}^{2}-1.99 \mathrm{z}+0.9914}
$$

\subsubsection{SOC Balancing Loop Compensator Design}

According to the small-signal model shown in Fig. 3, the uncompensated SOC loop gain (i.e., with unity SOC loop compensator gain) is given by (20) and its bode plot is represented by the dashed curve in Fig. 5 (b).

$T_{\text {socr-dhg-uncomp }}(z)=Z\left\{G_{i d r-d h g}(s) \cdot Z O H_{\text {icellr-dhg }}(s) \cdot G_{\text {socir-dhg }}(s) \cdot Z O H_{\text {socr-dhg }}(s) \cdot\right.$

$\left.(-1) \cdot V_{\text {bus }- \text { ref }} \cdot\left(\frac{1}{M_{v}}\right)\right\} \cdot G_{\text {dvref-dhg }}(z)$

where

$G_{d v r e f-d h g}(z)=\frac{Z\left\{Z O H_{v r-d h g} \cdot F_{m r-d h g} \cdot H_{c r-d h g}\right\} \cdot G_{v r-d h g}(Z)}{1+T_{v r-d h g}(z)}$ is the transfer function from the reference BPM output voltage $V_{\text {r-ref }}$ to duty cycle $d_{r}$ in discharge mode;

$Z O H_{\text {icellr-dhg }}(s)=\frac{1-e^{-s \cdot T_{s}}}{s}$

$Z_{\text {OOH }}$ socr-ang $(s)=\frac{1-e^{-s \cdot T_{s o c}}}{s} ; \mathrm{T}_{\mathrm{soc}}$ is the sampling period for the SOC value in the outer SOC balancing loop. Since the SOC value of a battery cell varies very slowly compared to the switching period of the power converter, the sampling rate of the outer SOC loop does not have to be very fast. $\mathrm{T}_{\mathrm{soc}}=1$ second is found to be a good trade-off between the hardware resource consumption, system stability and cell balancing speed.

With a compensator given by (21), the compensated SOC balancing loop gain achieves a control bandwidth of $0.0517 \mathrm{~Hz}$ and phase margin of $42.9^{\circ}$, as shown on the solid curve in Fig. 5 
(b). Due to the slow sampling rate of SOC value $(1 \mathrm{~Hz})$, it is expected that the control bandwidth of SOC balancing loop is much lower than that of inner BPM output voltage loop.

$$
G_{\text {SOCr-dhg }}(z)=\frac{1700529423.7}{\mathrm{z}-1}
$$

\section{Energy Sharing Controller Design in Constant Current Charging Mode}

\subsection{Small-Signal Model}

The charging operation is divided into two modes, i.e., constant current charging mode and constant voltage charging mode. This section will focus on constant current charging mode while the next section will focus on constant voltage charging mode. The basic control block diagrams of the energy sharing controlled distributed battery system operating in CCCM are shown in Fig. 6 where $\mathrm{V}_{\text {bus }}$ is the input/bus voltage; $\alpha_{\mathrm{i} 1} \ldots \alpha_{\mathrm{iN}}$ are the voltage loop multipliers; $\mathrm{M}_{\mathrm{i}}$ is the sum of the voltage loop multipliers; $I_{\text {cell-ref }}$ is the reference average cell current; $I_{\text {cell-avg }}$ is the average cell current; $\mathrm{G}_{\mathrm{vr}-\mathrm{chg}}, \mathrm{G}_{\text {socr-chg }}(\mathrm{r}=1,2, \ldots \mathrm{N})$ and $\mathrm{G}_{\mathrm{icell}}$ are the compensator for the BPM output voltage, SOC balancing control loop, and average cell current control loop, respectively. The energy sharing controller in CCCM operates in a similar fashion as in the discharge mode. The total input voltage $\mathrm{V}_{\text {bus }}$ of the charging source is shared among the BPMs based on the voltage multiplier values $\left(\alpha_{\mathrm{i} 1}\right.$ through $\left.\alpha_{\mathrm{iN}}\right)$ which are generated by the SOC balancing control loop. If a cell has a higher SOC value than the other cells, its voltage loop multiplier value will be smaller than that of the other cells. This will result in slower charge rate for this cell because the power delivered to each cell in this case is a function of the input voltage of the BPM for the same input current $I_{\text {in }}\left(I_{\text {in }}\right.$ is the opposite to $I_{\text {pack }}$ in Fig.1). In addition to the BPM input voltage and SOC balancing control loops, the energy sharing controller in CCCM consists of an average cell current control loop in order to ensure that the average cell charging current is regulated at the desired level (e.g. 0.5C). 


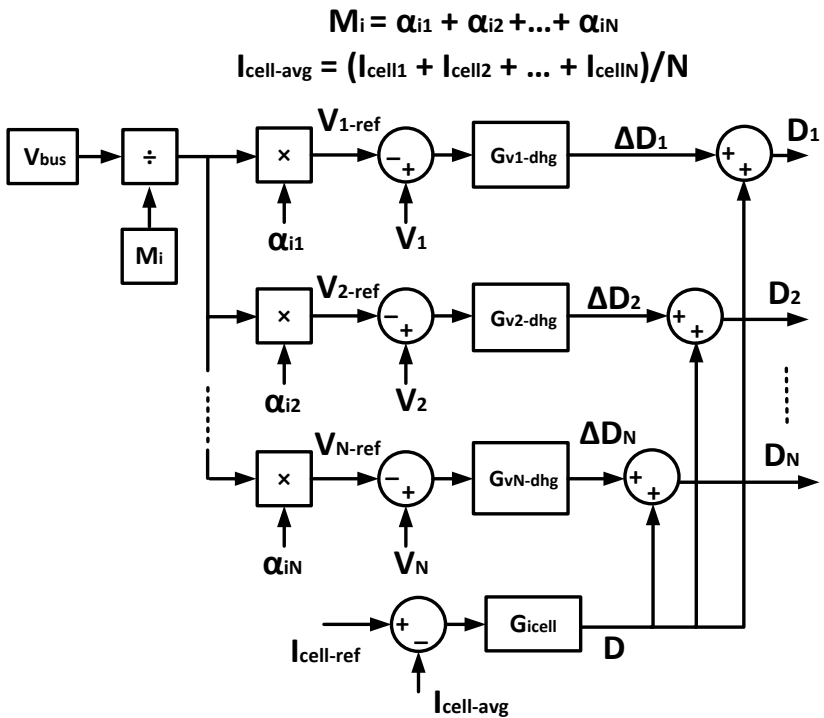

(a)

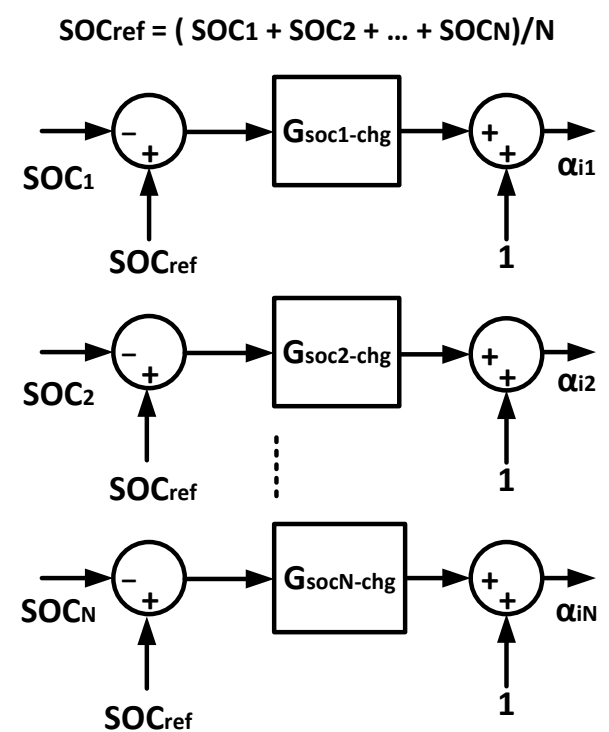

(b)

Fig. 6. Energy sharing controller's basic block diagram during CCCM operation: (a) the BPM input voltage control loop and average cell charging current control loop; (b) SOC balancing control loop [1].

Based on the basic control block diagrams shown in Fig. 6, the small-signal model for the energy sharing controlled distributed battery system in CCCM is derived as shown in Fig. 7. The transfer functions shown in Fig. 7 are described below. All the following transfer functions are for CCCM unless otherwise noted.

$T_{v r-c h g}(s):$ BPM output voltage control loop gain;

$T_{\text {socr-chg }}(s)$ : SOC balancing control loop gain;

$G_{v d r-c h g}(s)$ : duty cycle control to BPM input voltage transfer function;

$G_{i d r-c h g}(s)$ : duty cycle control to cell current transfer function;

$G_{\text {socir-chg }}(s)$ : cell current to cell SOC transfer function

$G_{v r-c h g}(z)$ : BPM input voltage control loop compensator;

$G_{\text {socr-chg }}(z)$ : SOC balancing control loop compensator;

$K_{d r-c h g}(s)$ : BPM input voltage sensing gain (including the input voltage sensor gain and the analog-to-digital converter gain); 


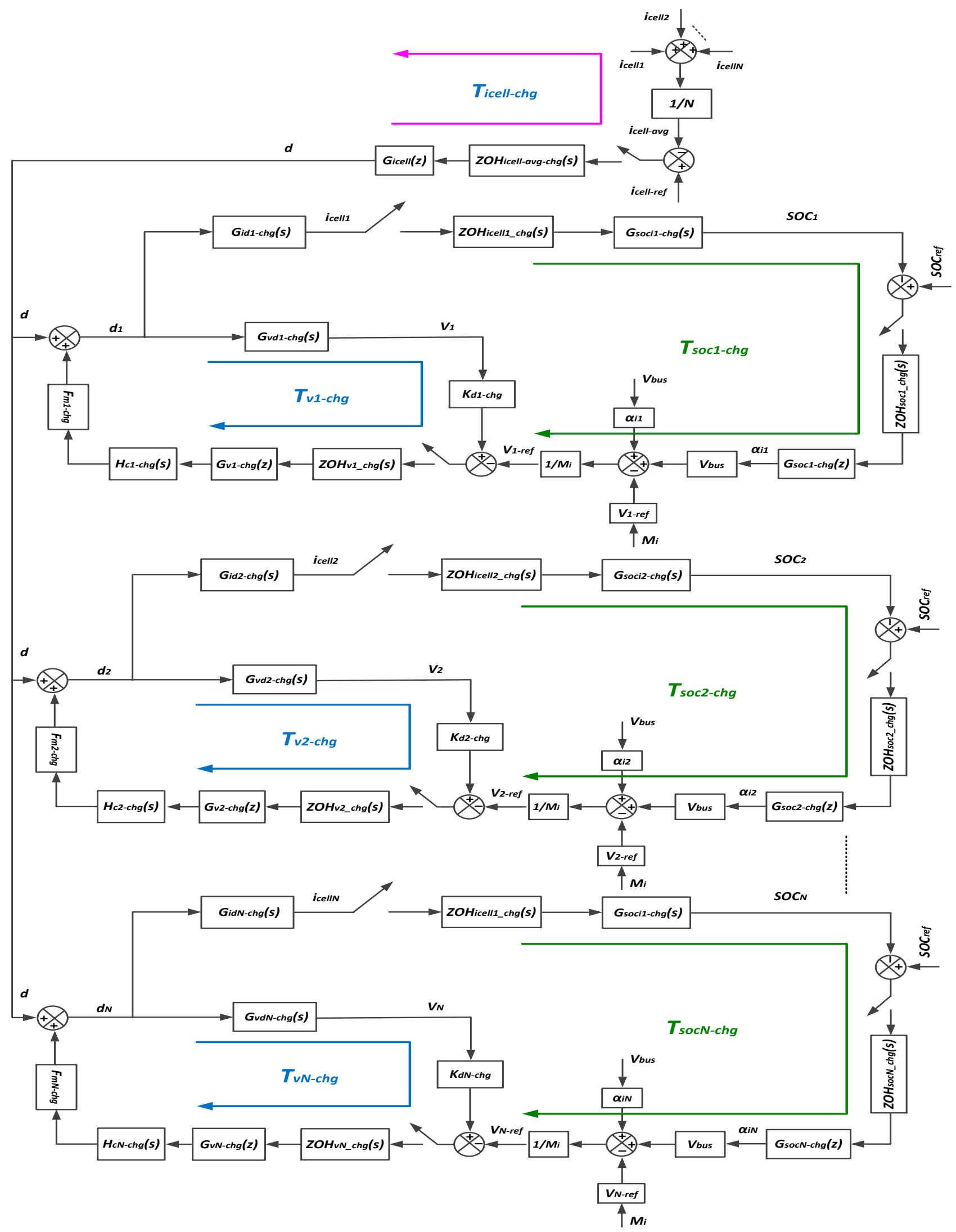

Fig. 7: Small-signal model of the energy-sharing controlled distributed battery system in CCCM. 
$F_{m r-c h g}(s):$ PWM modulator gain;

$H_{c r-c h g}(s)$ : digital controller computation delay model;

$\mathrm{ZOH}_{v r-c h g}(s)$ : zero order hold for BPM input voltage sampling ;

$Z O H_{\text {icellr-chg }}(s)$ : zero order hold model for cell current sampling;

$Z O H_{\text {socr-chg }}(s)$ : zero order hold model for cell SOC sampling.

$Z O H_{\text {socr-chg }}(s):$ zero order hold model for cell SOC sampling;

$\mathrm{ZOH}_{\text {icell-avg-chg }}(s)$ : zero order hold model for average cell current sampling.

Each BPM still consists of two independent control loops, i.e., BPM converter input voltage control loop and SOC control loop. In addition, all BPMs share an average cell current control loop. The following section presents derivation of the transfer functions associated with each control loop in CCCM.

\subsection{Derivation of Transfer Functions}

During charging operation, the converters operate as buck converters with the cells being the outputs as shown in Fig. 4 (the energy/current flow is reversed). The independent state variables of each BPM converter in this case are the inductor current or cell current $i_{\text {cell }}(t)$ and the BPM input voltage $v(t)$. The input variables are cell open circuit voltage $V_{o c}(t)$ and input current or pack current $i_{\text {pack }}(t)$. The output variables are the same as the state variables. The equilibrium operating point parameters used in CCCM are listed in Table 3.

Since the derivation of the transfer function in this case follows similar procedures as in discharge mode, the step-by-step derivation is not repeated here. The derived transfer functions are listed as follows,

$G_{v d r-c h g}(s)=\frac{v r(s)}{d r(s)}=\frac{\left(S L+Z_{c e l l}\right)\left(-\frac{I_{\text {pack }}}{D_{r}}\right)-\left(V_{o c r}+\frac{Z_{\text {cell }}}{D_{r}} I_{\text {pack }}\right)}{\left(S L+Z_{\text {cell }}\right) S C+D_{r}{ }^{2}}$ 


$$
\begin{aligned}
& G_{i d r-c h g}(s)=\frac{i \operatorname{cellr}(s)}{d r(s)}=\frac{-I_{\text {pack }}+S C\left(\frac{V_{o c r}}{D_{r}}+\frac{Z_{\text {cell }}}{D_{r}{ }^{2}} I_{\text {pack }}\right)}{\left(S L+Z_{\text {cell }}\right) S C+D_{r}{ }^{2}} \\
& G_{\text {socir }-\operatorname{chg}}(s)=\frac{\operatorname{SoCr}(s)}{i_{\operatorname{cell}(s)}}=\frac{T_{s}}{Q}
\end{aligned}
$$

Table 3

Equilibrium Operating Point Parameter Values in Charge Mode

\begin{tabular}{ll}
\hline Parameter & Value \\
\hline $\boldsymbol{V}_{\text {cellr }}$ & $3.7 \mathrm{~V}$ \\
$\boldsymbol{V}_{\boldsymbol{r}}$ & $8 \mathrm{~V}$ \\
$\boldsymbol{V}_{\text {bus }}$ & $16 \mathrm{~V}$ \\
$\boldsymbol{M}_{\boldsymbol{i}}$ & 2 \\
$\boldsymbol{\alpha}_{\boldsymbol{i l}}=\boldsymbol{\alpha}_{\boldsymbol{i} 2}$ & 1 \\
$\boldsymbol{Z}_{\text {cellr }}$ & $65 \mathrm{~m} \Omega$ \\
$\boldsymbol{I}_{\text {cell-ref }}$ & $1.3 \mathrm{~A}$ \\
$\boldsymbol{I}_{\text {pack }}$ & $0.615 \mathrm{~A}$ \\
$\boldsymbol{D}_{\boldsymbol{r}}$ & 0.4731 \\
$\boldsymbol{D}_{\boldsymbol{r}}{ }^{\prime}$ & 0.5269 \\
\hline
\end{tabular}

\subsection{Compensator Design}

\subsubsection{Voltage Loop Compensator Design}

According to the small signal model shown in Fig. 7, the discrete-time transfer function of the converter plant in $\mathrm{CCCM} \mathrm{G}_{\text {pr-chg }}(\mathrm{z})$ includes the $\mathrm{ZOH}$, the sampler, the BPM input voltage sensing gain $\mathrm{K}_{\mathrm{dr} \text {-chg, }}$, the digital controller computation delay model $\mathrm{H}_{\mathrm{cr}-\mathrm{chg}}$, in addition to the continuous-time plant $\mathrm{G}_{\mathrm{vdr}-\mathrm{chg}}(\mathrm{s}) . \mathrm{G}_{\mathrm{pr}-\mathrm{chg}}(\mathrm{z})$ is given by $(25)$ and its bode plot is represented by the dashed curve in Fig. 5 (c).

$$
\begin{aligned}
& G_{p r-c h g}(z)=Z\left\{-Z O H_{v r-c h g}(s) \cdot H_{c r-c h g}(s) \cdot F_{m r-c h g}(s) \cdot G_{v d r-c h g}(s) \cdot K_{d r-c h g}\right\}= \\
& \frac{0.0002245 z^{2}+0.0006576 z-0.0005437}{z^{3}-1.99 z^{2}+0.9914 z}
\end{aligned}
$$

Unlike the voltage loop design in discharge mode where the control bandwidth is limited by the RHP zero, the target control bandwidth for the voltage loop design in CCCM can be set higher. With a compensator given by (26), the BPM input voltage control loop gain $\left(\mathrm{T}_{\mathrm{vr}-}\right.$ 
$\left.\operatorname{chg}(\mathrm{z})=\mathrm{G}_{\mathrm{pr}-\mathrm{chg}}(\mathrm{z}) \cdot \mathrm{G}_{\mathrm{vr}-\mathrm{chg}}(\mathrm{z})\right)$ achieves a control bandwidth of $5.42 \mathrm{kHz}$ and a phase margin of $51^{\circ}$, as shown on the solid curve in Fig. 5 (c).

$G_{v r-\operatorname{chg}}(z)=\frac{449.9 \mathrm{z}^{2}-874.8 \mathrm{z}+425.2}{\mathrm{z}^{2}-1.669 \mathrm{z}+0.6687}$

\subsubsection{SOC Balancing Loop Compensator Design}

According to the small signal model shown in Fig. 7, the uncompensated SOC loop gain (i.e., with unity compensator gain) in CCCM is given by

$T_{\text {socr-chg-uncomp }}(z)=Z\left\{G_{\text {idr-chg }}(s) \cdot Z O H_{i c e l l r-c h g}(s) \cdot G_{\text {socir-chg }}(s) \cdot Z O H_{\text {socr-chg }} \cdot V_{\text {bus }} \cdot\left(\frac{1}{M_{i}}\right)\right\} \cdot$

$G_{\text {dvrefr-chg }}(z)$

where

$G_{\text {dvrefr-chg }}(z)=\frac{Z\left\{-Z O H_{v r-c h g} \cdot F_{m r-c h g} \cdot H_{c r-c h g}\right\} \cdot G_{v r-c h g}(z)}{1+T_{v r-c h g}(z)}$ is the transfer function from the reference output voltage $\mathrm{V}_{\mathrm{r}-\mathrm{ref}}$ to the duty cycle $\mathrm{d}_{\mathrm{r}}$ for $\mathrm{r}^{\text {th }}$ BPM in CCCM;

$Z O H_{\text {icellr-chg }}(s)=\frac{1-e^{-s \cdot T_{s}}}{s}$

$Z O H_{\text {socr }- \text { chg }}(s)=\frac{1-e^{-s \cdot T_{S O c}}}{s}$.

With a simple integrator given by (28), the outer SOC balancing control loop gain achieves a control bandwidth of $0.0851 \mathrm{~Hz}$ and a phase margin of $45.2^{\circ}$, as shown on the solid curve in Fig.5 (d).

$$
G_{\text {SOCr-chg }}(z)=\frac{3.379 \mathrm{e} 9 \mathrm{z}-1.46 \mathrm{e} 8}{\mathrm{z}-1}
$$

\subsubsection{Average Cell Current Loop Compensator Design}

According to the small-signal model shown in Fig. 7, the uncompensated average cell current control loop gain (i.e., with unity compensator gain) for a two-BPM system (used in the experimental prototype) is given by (29) and represented by dashed curve in Fig. 8 (a). 


$$
\begin{aligned}
& T_{\text {icell-chg-uncomp }}(z)=Z\left\{\frac{1}{2}\left(G_{\text {icelld } 1-\text { chg }}(s)+G_{\text {icelld } 2-\text { chg }}(s)\right) \cdot Z O H_{\text {icell-avg-chg }}(s)\right\}= \\
& \frac{1.059 \mathrm{z}^{3}-3.171 \mathrm{z}^{2}+3.167 \mathrm{z}-1.055}{\mathrm{z}^{4}-3.979 \mathrm{z}^{3}+5.941 \mathrm{z}^{2}-3.945 \mathrm{z}+0.9828}
\end{aligned}
$$

where $Z O H_{\text {icell-avg-chg }}(s)=\frac{1-e^{-s \cdot T_{s}}}{s}$

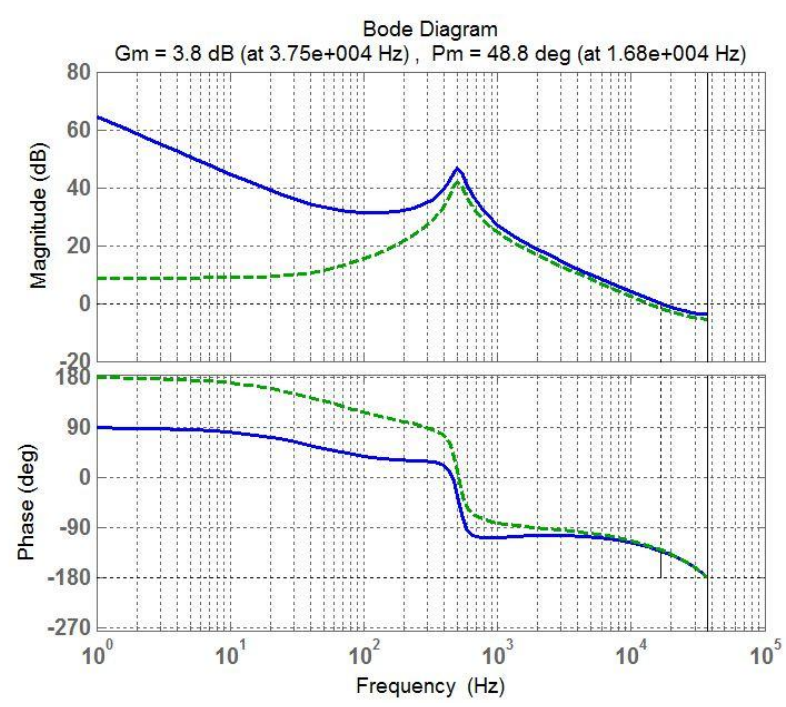

(a)

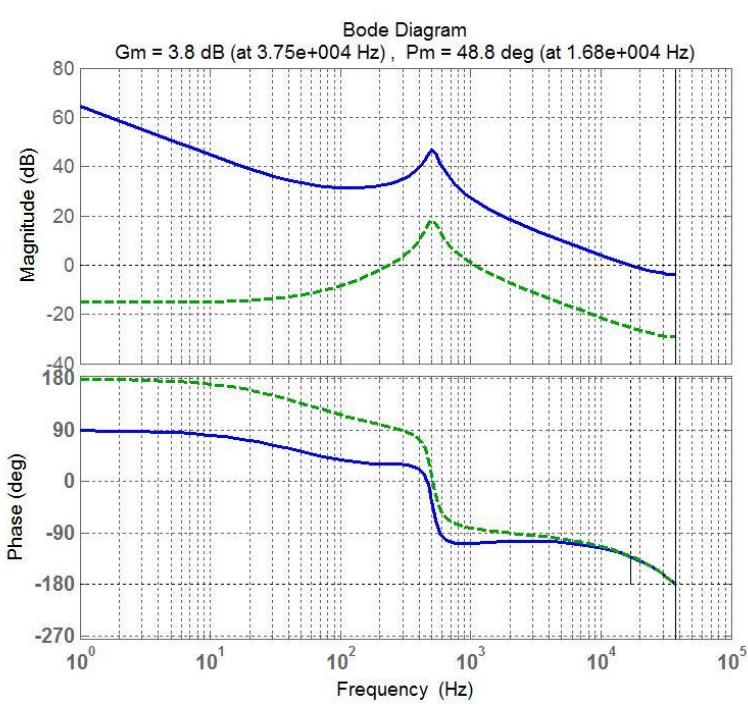

(b)

Fig. 8. The bode plot of uncompensated (dashed curve) and compensated (solid curve) for (a) Average cell current control loop gain in CCCM; (b) Average cell voltage control loop gain in CVCM; All at DC operating point.

With a compensator given by (30), the average cell current control loop gain achieves a control bandwidth of $16.8 \mathrm{kHz}$ and a phase margin of $48.8^{\circ}$ as shown on the solid curve in Fig. 8 (a).

$$
G_{\text {icell }}(z)=\frac{1.236 \mathrm{z}-1.184}{\mathrm{z}-1}
$$

\section{Energy Sharing Controller Design in Constant Voltage Charging Mode}

\subsection{Small-Signal Model}

Fig. 9 illustrates the basic control block diagram of the energy sharing controller during CVCM operation. The average cell voltage given by (31) is regulated at the maximum cell voltage reference value (e.g., $4.2 \mathrm{~V}$ for lithium-ion battery). 


$$
V_{\text {cell_avg }}=\left(V_{\text {cell1 } 1}+V_{\text {cell } 2}+\ldots+V_{\text {cellN }}\right) / \mathrm{N}
$$

Based on the basic control block diagram shown in Fig. 9, the small-signal model for the energy sharing controlled distributed battery system in constant voltage charging mode can be derived as shown in Fig. 10.

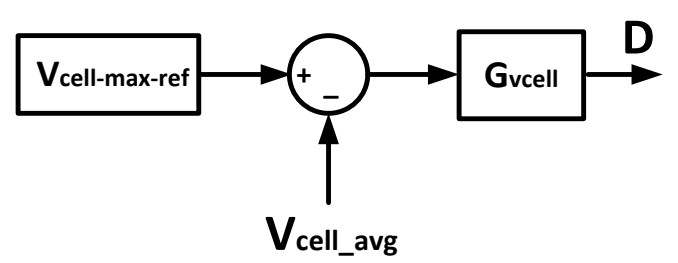

Fig. 9. The energy sharing controller's basic block diagram during CVCM operation.

The transfer functions shown in Fig. 10 are described below. All the following transfer functions are for CCCM unless otherwise noted.

$T_{v c e l l-c v c m}(z):$ average cell current control loop gain;

$G_{v c e l l r d-c h g}(s)$ : duty cycle control d to cell voltage $\mathrm{v}_{\text {cellr }}$ transfer function for $\mathrm{r}^{\text {th }}$ BPM;

$G_{v c e l l}(z):$ average cell voltage control loop compensator;

$\mathrm{ZOH}_{v \text { cell-avg-chg }}(s)$ : zero order hold model for average cell voltage sampling.

The control structure in this mode is relatively simple and consists of only a single control loop, i.e., average cell voltage control loop $\mathrm{T}_{\text {vcell-cvcm }}$, in order to regulate the average cell voltage at the desired level.



Fig. 10: Small-signal model of the energy-sharing controlled distributed battery system in CVCM. 


\subsection{Derivation of Transfer Function}

$G_{v c e l l r d-c h g}(s)=\frac{v c e l l r(s)}{d(s)}=\frac{i \operatorname{cellr}(s)}{d(s)} Z_{c e l l r}=\frac{-I_{\text {pack }}+S C\left(\frac{V_{o c r}}{D}+\frac{Z_{\text {cellr }}}{D^{2}} I_{\text {pack }}\right)}{\left(S L+Z_{\text {cellr }}\right) S C+D^{2}} Z_{c e l l r}$

\subsection{Average Cell Voltage Loop Compensator Design}

According to the small-signal model shown in Fig. 10, the uncompensated average cell voltage control loop gain (i.e, with unity compensator gain) for a two-BPM system is given by (33) and is represented by the dashed curve in Fig. 8 (b).

$T_{v c e l l-c v c m-u n c o m p}(z)=Z\left\{\frac{1}{2}\left(G_{v c e l l 1 d-c h g}(s)+G_{v c e l l 2 d-c h g}(s)\right) \cdot Z O H_{v c e l l-a v g-c h g}(s)\right\}=$ $\frac{0.06885 z^{3}-0.2061 z^{2}+0.2059 z-0.06857}{z^{4}-3.979 z^{3}+5.941 z^{2}-3.945 z+0.9828}$

where $Z O H_{v c e l l-a v g-c h g}(s)=\frac{1-e^{-s \cdot T_{s}}}{s}$.

With a compensator given by (34), the average cell voltage control loop gain achieves a control bandwidth of $16.8 \mathrm{kHz}$ and phase margin of $48.8^{\circ}$, as shown in Fig. 8 (b).

$$
G_{v c e l l}(z)=\frac{19.02 \mathrm{z}-18.22}{\mathrm{z}-1}
$$

\section{Validity of Models and Stability Evaluation Across the Entire Range of Operation}

As it is the case for the small-signal models of all switch-mode power converters with variety of control schemes and source/load types, a given operating set-point is chosen to optimize the dynamic performance while maintaining sufficient stability margins. Then the set-point is varied in order to make sure that the dynamics and stability requirements are also satisfied across the entire range of operation.

In the presented model of the energy sharing distributed battery architecture, the cell voltage varies between $3 \mathrm{~V}-4.2 \mathrm{~V}$ (lithium-ion chemistry) and the output voltage of each battery power module is regulated between $6 \mathrm{~V}-10 \mathrm{~V}$ depending on the difference between the SOC values of the cells. The nominal DC operating point of each battery power module is selected at $\mathrm{V}_{\text {cell }}=3.7 \mathrm{~V}$ 
(which covers most of the SOC range of a lithium-ion battery cell) and $\mathrm{V}_{\mathrm{o}}=8 \mathrm{~V}$. This $\mathrm{DC}$ operating point is chosen because once the cell balancing is achieved, the output voltage of each battery module should be balanced at around $8 \mathrm{~V}$ in order to draw the same amount of power from each cell in order to maintain a balanced SOC condition between the cells.

Once the design criteria are met and optimized at the nominal DC operating point, the setpoint is varied to the following two extreme conditions:

1. Battery cell is fully discharged, i.e., $\mathrm{V}_{\text {cell }}=3 \mathrm{~V}$; The $\mathrm{SOC}$ values of the cells are significantly different and the output voltage of the battery power module is regulated at the maximum value, i.e., $\mathrm{V}_{\mathrm{o}}=10 \mathrm{~V}$.

2. Battery cell is fully charged, i.e., $\mathrm{V}_{\text {cell }}=4.2 \mathrm{~V}$; The $\mathrm{SOC}$ values of the cells are significantly different and the output voltage $\mathrm{V}_{\mathrm{o}}$ of the battery power module is regulated at the minimum value, i.e., $\mathrm{V}_{\mathrm{o}}=6 \mathrm{~V}$.

The bode plots of the various control loops in discharge and charge mode are shown in Fig. 11 and 12, respectively, for the two extreme conditions mentioned above. As can be observed, the crossover frequency/bandwidth and stability margins also meet the design criteria at the two extreme conditions. 


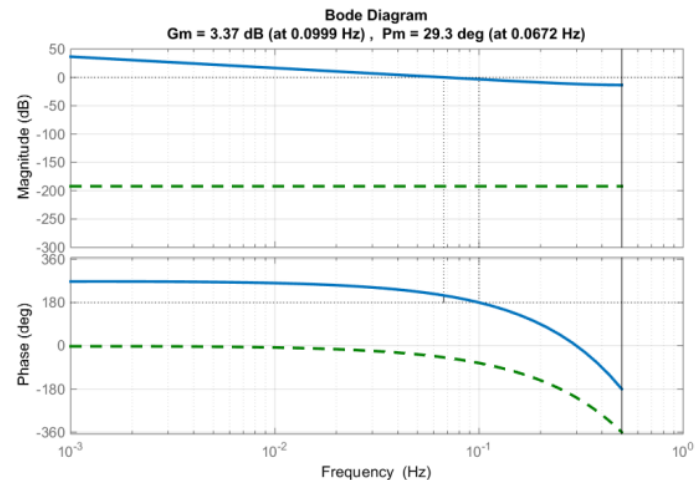

(a)

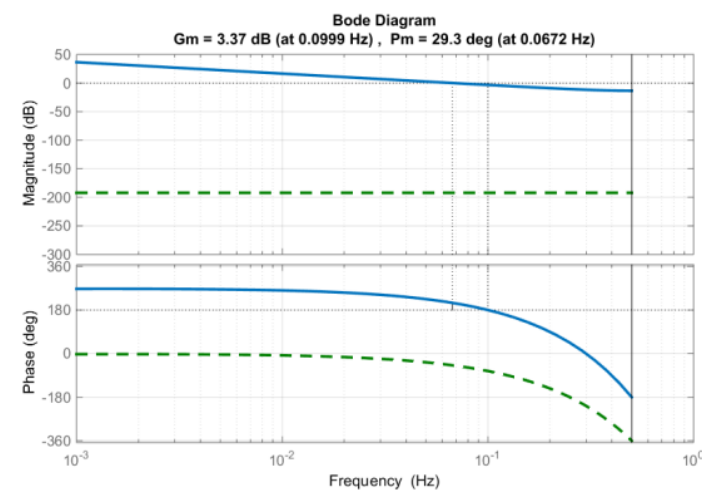

(c)

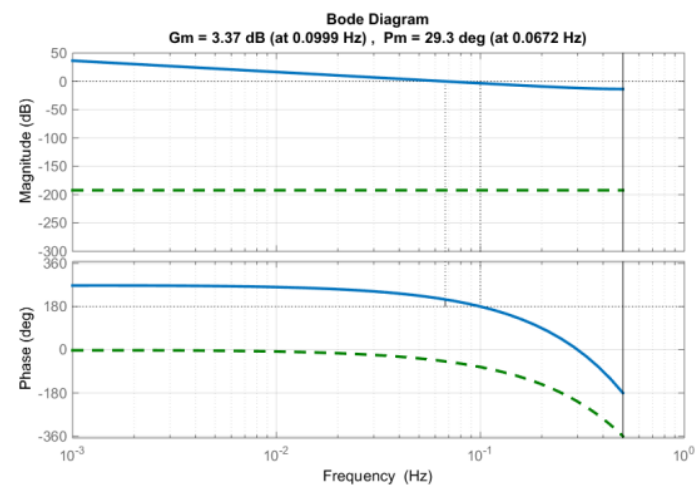

(e)

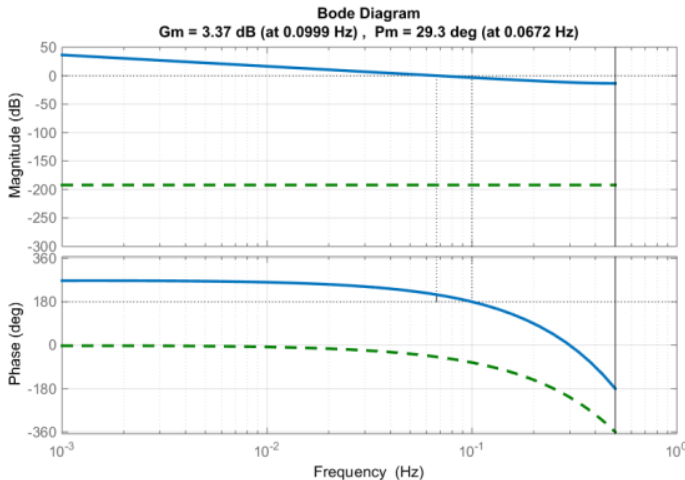

(b)

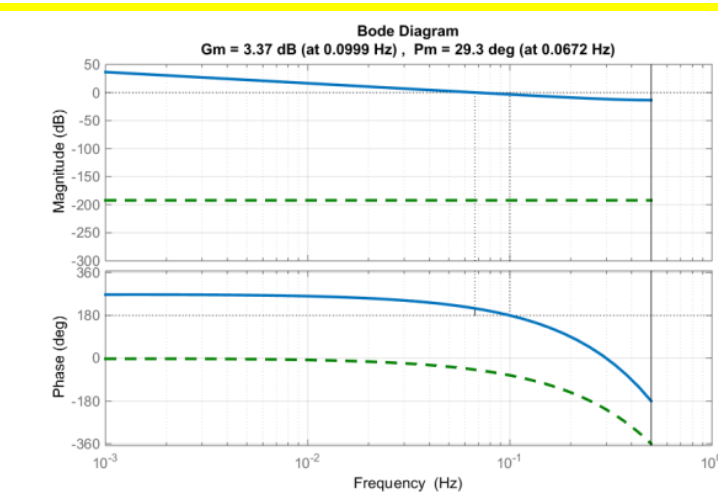

(d)

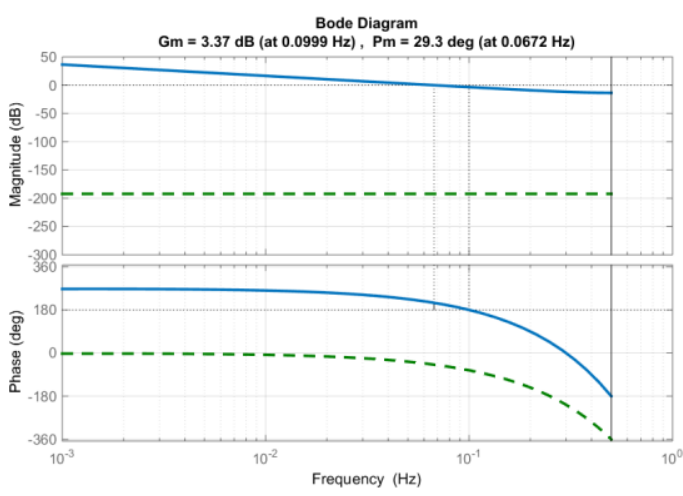

(f)

Fig. 11. The bode plot of the uncompensated (dashed curve) and compensated (solid curve) for (a) BPM output voltage loop gain in discharge mode; (b) SOC balancing loop gain in discharge mode; (c) BPM input voltage loop gain in CCCM; (d) SOC balancing loop gain in CCCM; (e) Average cell current control loop gain in CCCM; (f) Average cell voltage control loop gain in $\mathrm{CVCM}$; All at extreme operating point $\mathrm{V}_{\text {cell }}=3 \mathrm{~V}$ and $\mathrm{V}_{0}=10 \mathrm{~V}$. 




(a)

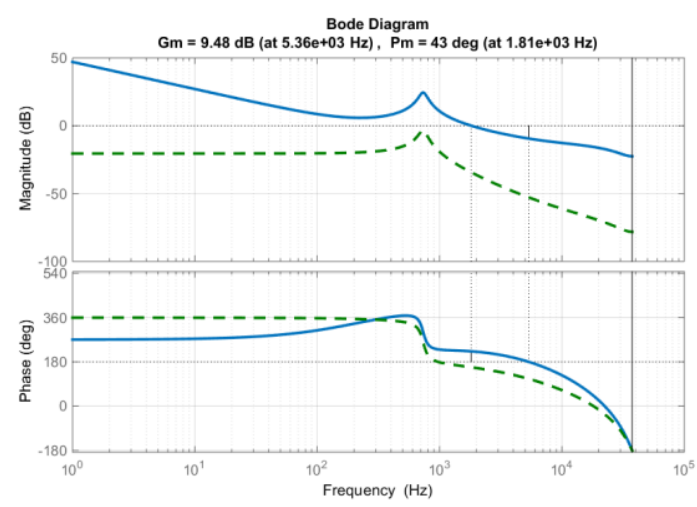

(c)

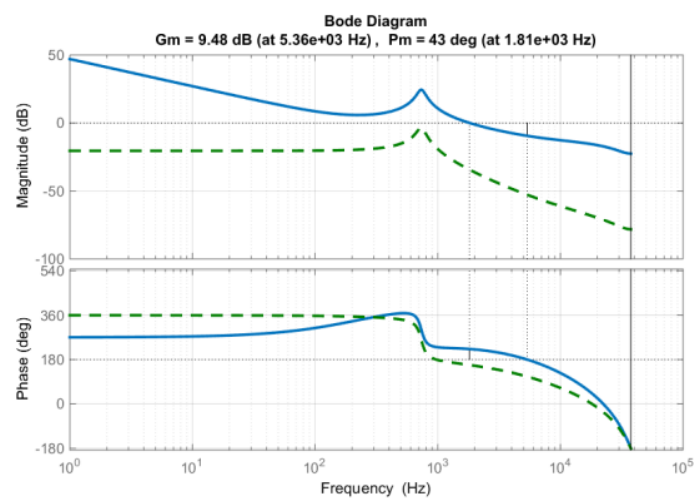

(e)

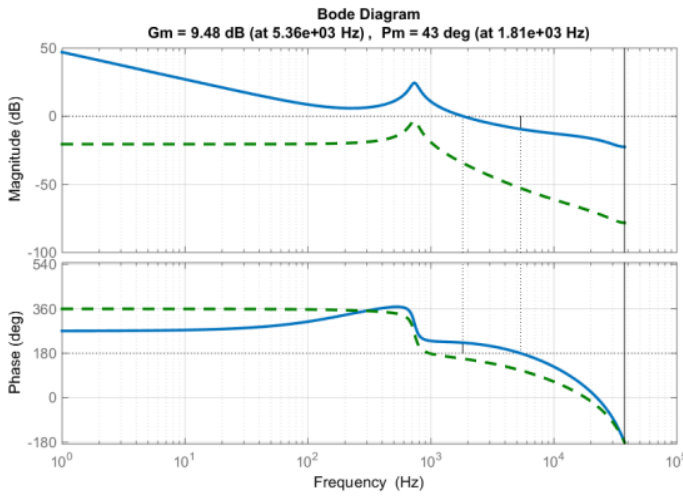

(b)

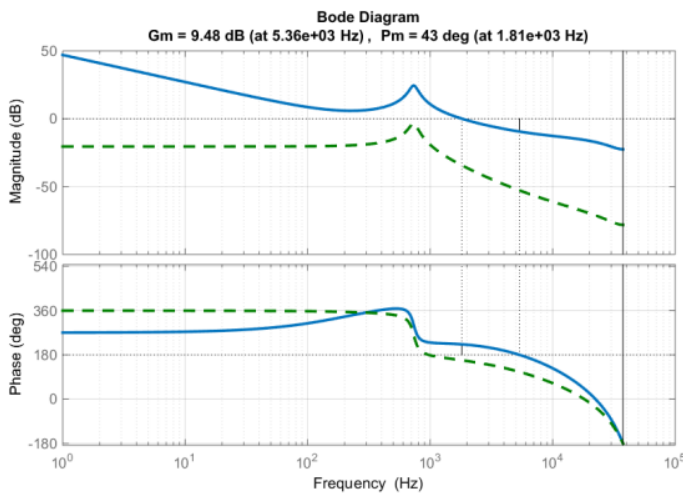

(d)

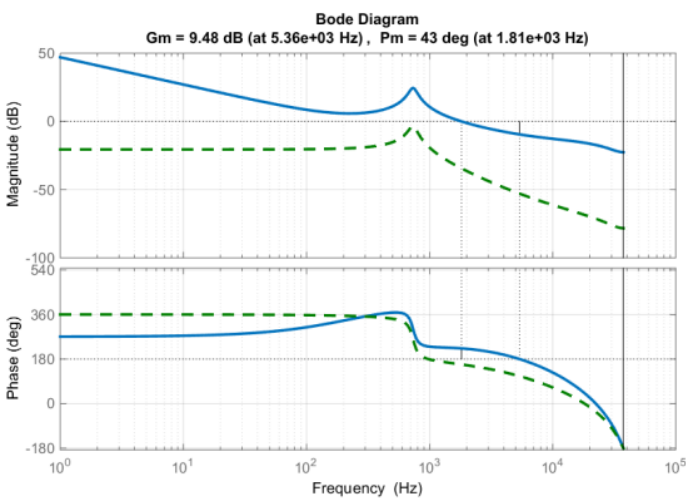

(f)

Fig. 12. The bode plot of the uncompensated (dashed curve) and compensated (solid curve) for (a) BPM output voltage loop gain in discharge mode; (b) SOC balancing loop gain in discharge mode; (c) BPM input voltage loop gain in CCCM; (d) SOC balancing loop gain in CCCM; (e) Average cell current control loop gain in CCCM; (f) Average cell voltage control loop gain in $\mathrm{CVCM}$; All at extreme operating point $\mathrm{V}_{\text {cell }}=4.2 \mathrm{~V}$ and $\mathrm{V}_{\mathrm{o}}=6 \mathrm{~V}$. 


\section{Simulation and Experimental Model Validation}

While each control loop design varies with the mode of operation, the general rule of thumb design criteria include:

a) High control bandwidth /crossover frequency (at least $10 \%$ of the switching frequency of the BPU) for the voltage control loop in order to ensure fast transient response to load variation and other system disturbances.

b) The SOC control loop is inherently slow due to the slow changing nature of the SOC value of the battery cell (sampling rate of the SOC value is also low, i.e., 1Hz).

c) Sufficient stability margins (minimal phase margin of $45^{\circ}$ and gain margin of $6 \mathrm{~dB}$ ) for all the control loops in order to ensure system stability under all operation conditions.

In addition to the compensator parameters, there are several other parameters that also play important roles in the control loop design, i.e., sampling frequency of the battery cell voltage and the SOC value of each cell. In the proposed battery system, the sampling frequency of the battery cell voltage is the same as the switching frequency of the BPU. If higher sampling frequency is used, the sampled value may be more accurate (closer to the analog value), but the tradeoff would be faster ADC and processor speed in addition to more power consumption. As mentioned earlier, the cell SOC value varies very slowly (in the order of minutes during most part of the discharging/charging process), so the SOC sampling rate is set to $1 \mathrm{~Hz}$ in the manuscript which is found to be a good trade-off between the hardware resource consumption, system stability and cell balancing speed.

The derived small-signal models and designed compensators for different operating modes are validated using both simulation model and proof-of-concept experimental prototype (hardware). The simulation model (a mathematical block diagram based system model based on the derived 
transfer functions) is built in MATLAB®/SIMULIK software package. The designed compensators for different control loops are implemented by using TMS320S28335 microcontroller and tested on a two-cell distributed battery system prototype. The design parameters of the simulation model and experimental prototype are the same and they are as listed in Table 2. The simulation and experimental results are shown in Fig. 14 for discharging operation and in Fig. 15 for charging operation.

It is important to note that the MATLAB®/SIMULIK mathematical simulation model utilizes the derived small-signal transfer functions equations and compensators obtained in this paper, as shown in Fig. 13. Therefore, if the resulted system dynamic responses from the experimental hardware match the dynamic responses obtained from the MATLAB®/SIMULIK simulation model, this implies that the developed small-signal model and compensators in this paper are valid. 




(a)

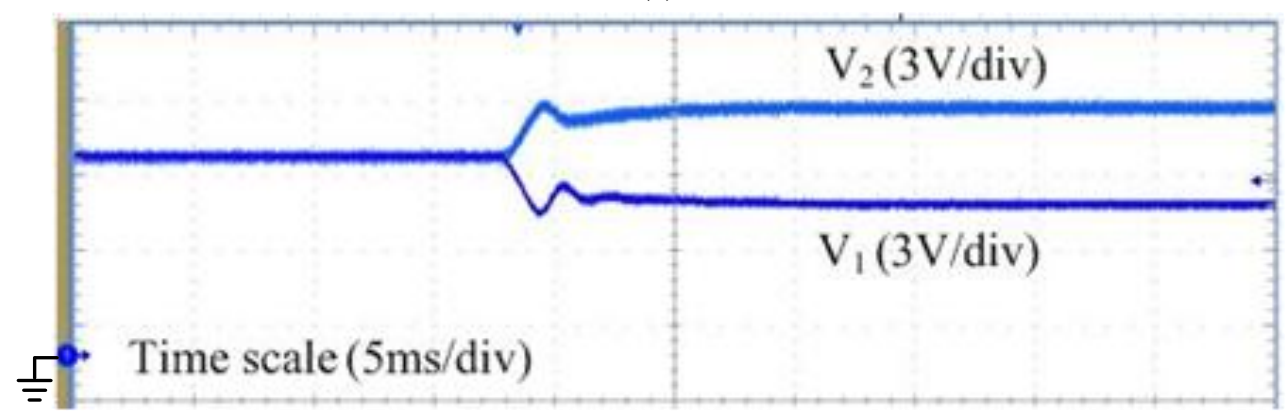

(b)

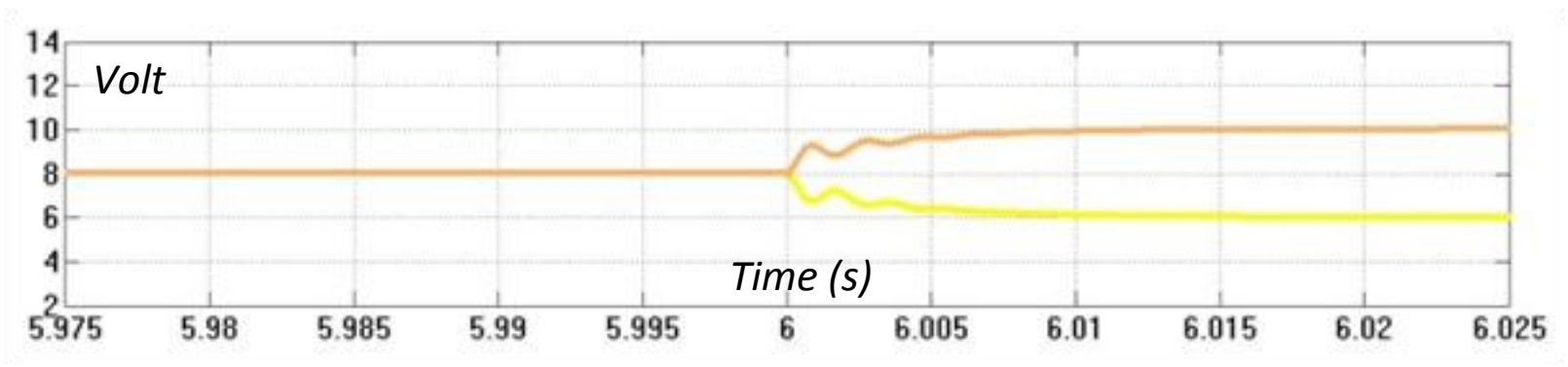

(c)



(d)

Fig. 14. (a) Simulation model waveforms (top trace: $\mathrm{V}_{2}$; bottom trace: $\mathrm{V}_{1}$; horizontal axis unit: second; vertical axis unit: volt) ; (b) experimental waveforms for the BPM output voltages when $\mathrm{V}_{1 \text {-ref }}$ is changed from $8 \mathrm{~V}$ to $6 \mathrm{~V}$ while $\mathrm{V}_{\text {2-ref }}$ is changed from $8 \mathrm{~V}$ to $10 \mathrm{~V}$ in discharge mode; (c) simulation model waveforms and (d) experimental waveforms for the BPM output voltages when SOC1 is suddenly changed from $80 \%$ to $75 \%$ under cell balanced condition where $\mathrm{SOC}_{1}=\mathrm{SOC}_{2}=80 \%$ in discharge mode. 
For discharging operation testing, the performance of the inner BPM output voltage control loop is first tested by disabling the SOC control loop. The voltage loop multipliers $\left(\alpha_{\mathrm{v} 1}\right.$ and $\left.\alpha_{\mathrm{v} 2}\right)$ are initially set to 1 which results in $\mathrm{V}_{1 \text {-ref }}=\mathrm{V}_{2 \text {-ref }}=8 \mathrm{~V}$. Then the voltage loop multiplier values are varied against each other with $\alpha_{\mathrm{v} 1}$ being set to the minimum value 0 while $\alpha_{\mathrm{v} 2}$ is set to the maximum value 2. This leads to $V_{1-\text { ref }}=6 \mathrm{~V}$ and $V_{2 \text {-ref }}=10 \mathrm{~V}$. As shown in Fig. 14 (a) and (b), the simulation model results and the experimental results for each BPM output voltage agree well with each other, i.e., they have the same response behavior such as shape, magnitude, and timing.

Then, the dynamics of the outer SOC control loop is tested in discharge mode (in this test, all loops including SOC balancing loop are enabled/functional). The SOC value of the cell by nature changes very slowly under normal discharge rates $(0.5 \mathrm{C}-2 \mathrm{C})$ and as specified by the manufacturer of the battery cells. Therefore the SOC value of cell1 is intentionally and manually varied/stepped by $5 \%$ ( $80 \%$ to $75 \%$ in this case) in order to create a fast transient condition of SOC for testing purpose (This is done by stepping the estimated SOC value in the microcontroller by 5\%). As the SOC value of cell1 is reduced to be lower than that of cell2, the SOC control loop automatically sets the voltage loop multiplier of BPM2 to be higher than that of BPM1 in order to discharge BPM2 faster than BPM1. As shown in Fig. 14 (c) and (d), the output voltage of BPM2 is regulated by the closed-loop system at the maximum value while that of BPM1 is regulated at the minimum value. The simulation model results also agree well with the experimental results as can be observed from Fig. 14. 


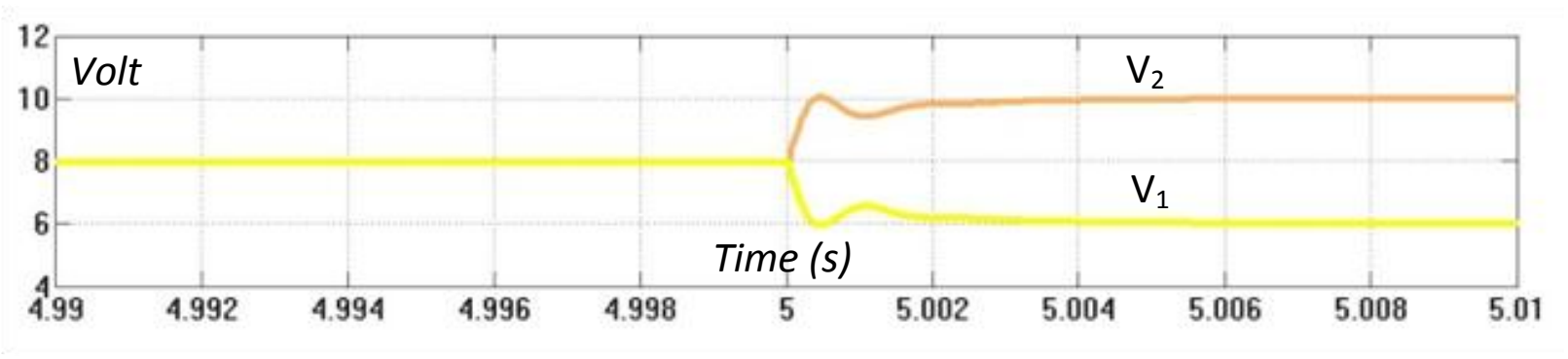

(c)

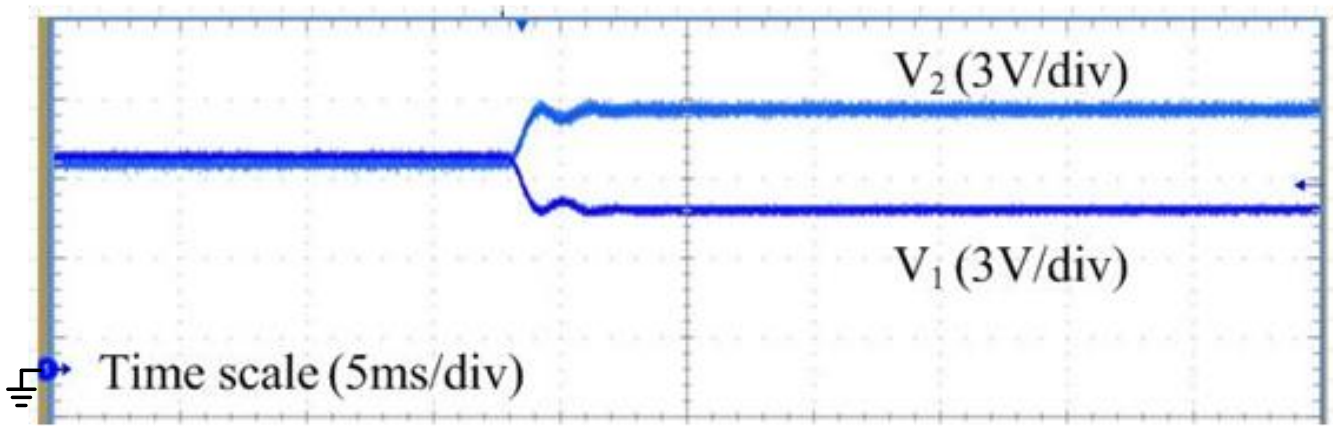

(d)

Fig. 15. (a) Simulation model waveforms (top trace: $\mathrm{V}_{2}$; bottom trace: $\mathrm{V}_{1}$; horizontal axis unit: second; vertical axis unit: volt) and (b) experimental waveforms for the BPM output voltages when $\mathrm{V}_{\text {1-ref }}$ is changed from $8 \mathrm{~V}$ to $6 \mathrm{~V}$ while $\mathrm{V}_{\text {2-ref }}$ is changed from $8 \mathrm{~V}$ to $10 \mathrm{~V}$ in charge mode. (c) Simulation model waveforms and (d) experimental waveforms for the BPM output voltages when $\mathrm{SOC}_{1}$ is suddenly changed from $80 \%$ to $85 \%$ under cell balanced condition where $\mathrm{SOC}_{1}=\mathrm{SOC}_{2}=80 \%$ in charge mode. 
For the model and control verification during charging operation, similar test procedures are performed as for the discharge mode. The only difference in the testing condition is that for the charging operation, the SOC value of cell1 is manually varied/stepped in the opposite direction from $80 \%$ to $85 \%$ in order to create the fast transient condition of SOC for testing the dynamics of the SOC balancing control loop. The waveforms shown in Fig. 15 demonstrate the consistency between the simulation model and experimental results.

\section{CONCLUSION}

State-space averaging small-signal modeling and analysis is performed in this paper in order to gain deeper insights into the dynamics of the energy sharing controlled distributed battery system and facilitate the design of the energy sharing controller. Based on the derived smallsignal models and associated transfer functions, all of the control loops are compensated under each operation mode including discharge mode, constant current charging mode and constant voltage charging mode by using rule-of-thumb frequency-domain design guidelines and criteria, such as control bandwidth and stability margins. The derived small-signal models and compensators design are validated by both simulations and a two-cell distributed battery system experimental prototype. 


\section{ACKNOWLEDGMENTS}

This material is based upon work supported in part by the National Science Foundation under

Grant No.1509824. Any opinions, findings and conclusions or recommendations expressed in this material are those of the author(s) and do not necessarily reflect the views of the National Science Foundation.

This work is also supported in part by The Center for Advanced Vehicle Technologies (CAVT) at The University of Alabama - Tuscaloosa (UA). Any opinions, findings and conclusions or recommendations expressed in this material are those of the author(s).

\section{REFERENCES}

[1] Wangxin Huang and Jaber Abu Qahouq, "Energy sharing control scheme for state-of-charge balancing of distributed battery energy storage system," IEEE Transactions on Industrial Electronics, Vol.62, No. 5, Page(s): 2764-2776, May 2015.

[2] Nilanjan Mukherjee, and Dani Strickland, "Control of cascaded DC-DC converter based hybrid battery energy storage systems - part I: stability issue", IEEE Trans. Ind. Electron., DOI: 10.1109/TIE.2015.2509911, as of Jan 2016.

[3] A. Kuperman, U. Levy, J. Goren, A. Zafransky, and A. Savernin, " Battery Charger for Electric Vehicle Traction Battery Switch Station," IEEE Trans. Ind. Electron., vol. 60, no. 12, pp. 5391- 5399, Dec. 2013.

[4] David Velasco de la Fuente, Cesar L. Trujillo Rodriguez, and Gabriel Garcera, " Photovoltaic Power System with Battery Backup with Grid-Connection and Islanded Operation Capabilities, " IEEE Trans. Ind. Electron., vol. 60, no. 4, pp. 1571-1581, April 2013.

[5] Manuela Sechilariu, Baochao Wang, and Fabrice Locment, " Building Integrated Photovoltaic System with Energy Storage and Smart Grid Communication, " IEEE Trans. Ind. Electron., vol. 60, no. 4, pp. 1607- 1618, April 2013.

[6] H. Rahimi-Eichi, F. Baronti, and M.-Y.Chow, "Online adaptive parameter identification and state-of-charge coestimation for lithium-polymer battery cells," IEEE Trans. Ind. Electron., vol. 61, no. 4, pp. 2053-2061, April 2014.

[7] Wangxin Huang and Jaber A. Abu Qahouq, "An online battery impedance measurement method using DC-DC power converter control," IEEE Trans. Ind. Electron., vol. 61, no. 11, pp. 5987-5995, Nov. 2014.

[8] Mehdi Gholizadeh and Farzad R. Salmasi, "Estimation of state of charge, unknown nonlinearities, and state of health of a lithium-ion battery based on a comprehensive unobservable Model," IEEE Trans. Ind. Electron., vol. 61, no. 3, pp. 1335-1344, Mar. 2014.

[9] Mehrnoosh Shahriari and Mohammad Farrokhi,,"Online state-of-health estimation of VRLA batteries using state of charge," IEEE Trans. Ind. Electron., vol. 60, no. 1, pp. 191-202, Jan. 2013.

[10] A. Imtiaz and F. H. Khan, "Time shared flyback converter based regenerative cell balancing technique for series connected li-ion battery strings," IEEE Trans. Power Electron., vol. 28, no.12, pp. 5960 - 5975 Dec. 2013.

[11] A. Manenti, A. Abba, A. Merati, S. M. Saaresi, and A. Geraci, "A New BMS Architecture Based on Cell Redundancy," IEEE Trans. Ind. Electron., vol. 58, no. 9, pp. 4314-4322, Sept. 2011. 
[12] Yanqi Zheng, Marco Ho, Jianping Guo, Ki-Leung Mak, and Ka Nang Leung, "A single-inductor multipleoutput auto-buck-boost DC-DC converter with autophase allocation," IEEE Transactions on Power Electronics, Vol. 31, No. 3, Page(s): 2296-2313, March 2016.

[13] Hector Sarnago, Oscar Lucia, Arturo Mediano, and Jose M. Burdio, "Design and implementation of a highefficiency multiple-output resonant converter for induction heating applications featuring wide bandgap devices," IEEE Transactions on Power Electronics, Vol. 29, No. 5, Page(s): 2296-2313, May 2014.

[14] O. A. Ahmed, J.A. M. Bleijs, "Modeling and experimental verification of the effect of parasitic elements on the performance of an active-clamped current-fed DC-DC converter", Simulation Modeling Practice and Theory, Vol. 59, Page(s): 71-88, Dec. 2015.

[15] Ahmad Saudi Samosir, Abdul Halim Mohd Yatim, "Dynamic evolution control for synchronous buck DC-DC converter: Theory, modeling and simulation", Simulation Modeling Practice and Theory, Vol. 18, No. 5, Page(s): 663-676, May. 2010.

[16] Amin Mirzaei, Awang Jusoh, Zainal Salam, Ehsan Adib, Hosein Farzanehfard, "Analysis and design of a high efficiency bidirectional DC-DC converter for battery and ultracapacitor applications", Simulation Modeling Practice and Theory, Vol. 19, No. 7 Page(s): 1651-1667, August 2011.

[17] Marisol Delgado, Hebertt Sira-Ramirez, "A bond graph approach to the modeling and simulation of switch regulated DC-to-DC power supplies", Simulation Modeling Practice and Theory, Vol. 6, No. 7 Page(s): 631646, Nov. 1998.

[18] S. Krithiga, N. Ammasai Gounden, "Invefstigations of an improved PV system topology using multilevel boost converter and line commutated inverter with solutions to grid issues", Simulation Modeling Practice and Theory, Vol. 42, Page(s): 147-159, March 2014.

[19] Mohd Rodhi Sahid, Abdul Halim Mohd Yatim, "Modeling and simulation of a new bridgeless SEPIC power factor correction circuit", Simulation Modeling Practice and Theory, Vol. 19, No. 2, Page(s): 599-611, Feb 2011.

[20] Erickson, Robert W., and Dragan Maksimovic. Fundamentals of power electronics. Springer Science \& Business Media, 2007. 
Table 1

Equilibrium (DC) Operating Point Parameter Values in Discharge Mode

\begin{tabular}{ll}
\hline Parameter & Value \\
\hline$V_{\text {cellr }}$ & $3.7 \mathrm{~V}$ \\
$V_{r}$ & $8 \mathrm{~V}$ \\
$V_{\text {bus-ref }}$ & $16 \mathrm{~V}$ \\
$M_{v}$ & 2 \\
$\alpha_{v 1}=\alpha_{v 2}$ & 1 \\
$Z_{\text {cellr }}$ & $65 \mathrm{~m} \Omega$ \\
$I_{\text {pack }}$ & $0.65 \mathrm{~A}$ \\
$D_{r}$ & 0.5492 \\
$D_{r}{ }^{\prime}$ & 0.4508 \\
\hline
\end{tabular}

Table 2

Main BPM Design Parameters

\begin{tabular}{ll}
\hline Parameter & Value \\
\hline$V_{\text {in }}=V_{\text {cell }}$ & $3 \mathrm{~V}-4.2 \mathrm{~V}$ \\
$V_{r}$ & $6 \mathrm{~V}-10 \mathrm{~V}$ \\
$L$ & $100 \mu \mathrm{H}$ \\
$C_{o}$ & $220 \mu \mathrm{F}$ \\
$f_{\text {sw }}$ & $150 \mathrm{kHz}$ \\
$I_{\text {pack }}($ nominal $)$ & $0.65 \mathrm{~A}$ \\
$Q($ rated $)$ & $2.6 \mathrm{Ah}$ \\
\hline
\end{tabular}

Table 3

Equilibrium Operating Point Parameter Values in Charge Mode

\begin{tabular}{ll}
\hline Parameter & Value \\
\hline $\boldsymbol{V}_{\text {cellr }}$ & $3.7 \mathrm{~V}$ \\
$\boldsymbol{V}_{\boldsymbol{r}}$ & $8 \mathrm{~V}$ \\
$\boldsymbol{V}_{\text {bus }}$ & $16 \mathrm{~V}$ \\
$\boldsymbol{M}_{\boldsymbol{i}}$ & 2 \\
$\boldsymbol{\alpha}_{\boldsymbol{i l}}=\boldsymbol{\alpha}_{\boldsymbol{i} 2}$ & 1 \\
$\boldsymbol{Z}_{\text {cellr }}$ & $65 \mathrm{~m} \Omega$ \\
$\boldsymbol{I}_{\text {cell-ref }}$ & $1.3 \mathrm{~A}$ \\
$\boldsymbol{I}_{\text {pack }}$ & $0.615 \mathrm{~A}$ \\
$\boldsymbol{D}_{\boldsymbol{r}}$ & 0.4731 \\
$\boldsymbol{D}_{\boldsymbol{r}}{ }^{\prime}$ & 0.5269 \\
\hline
\end{tabular}




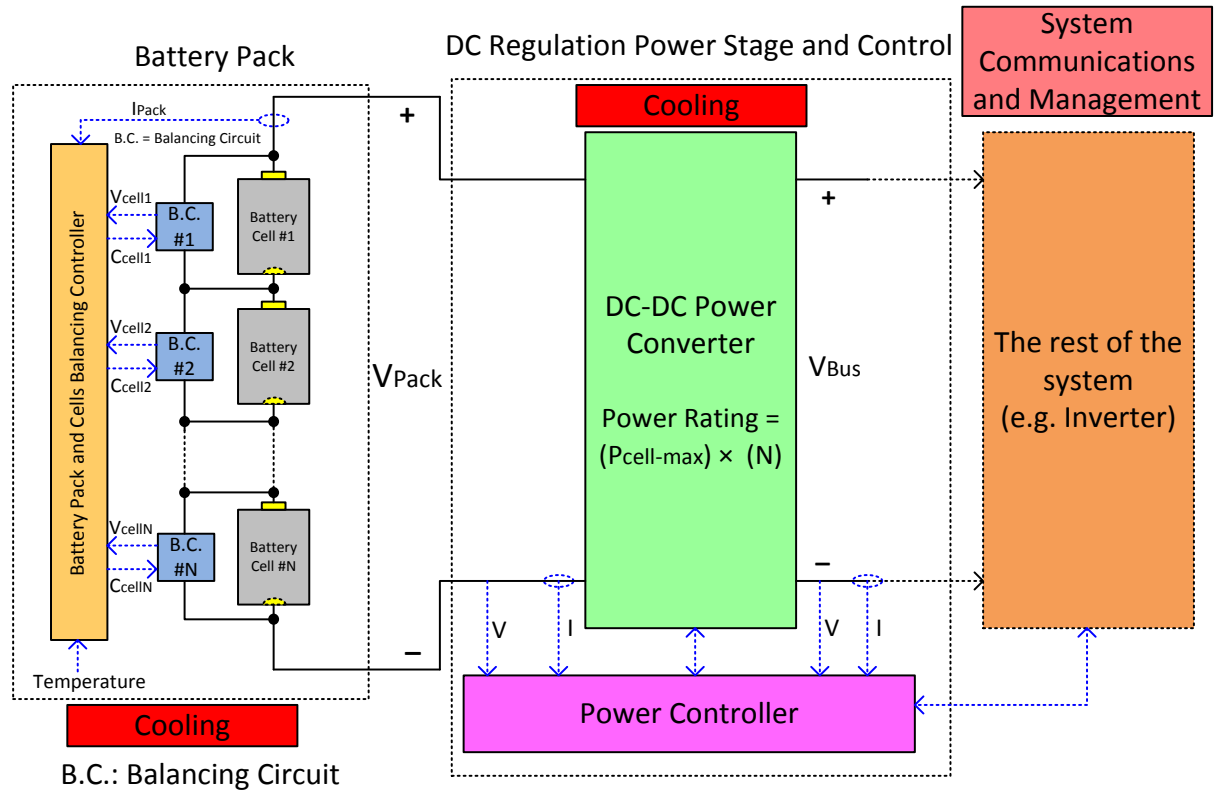

(a)

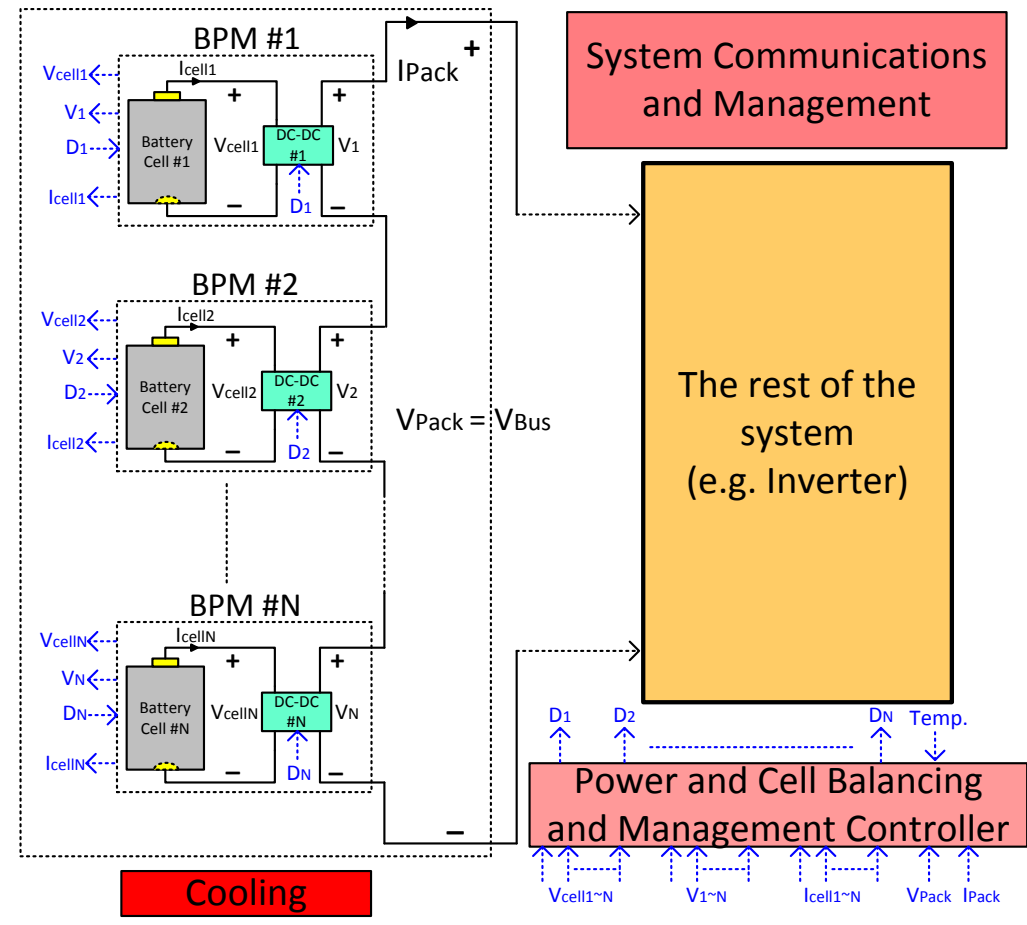

(b) 


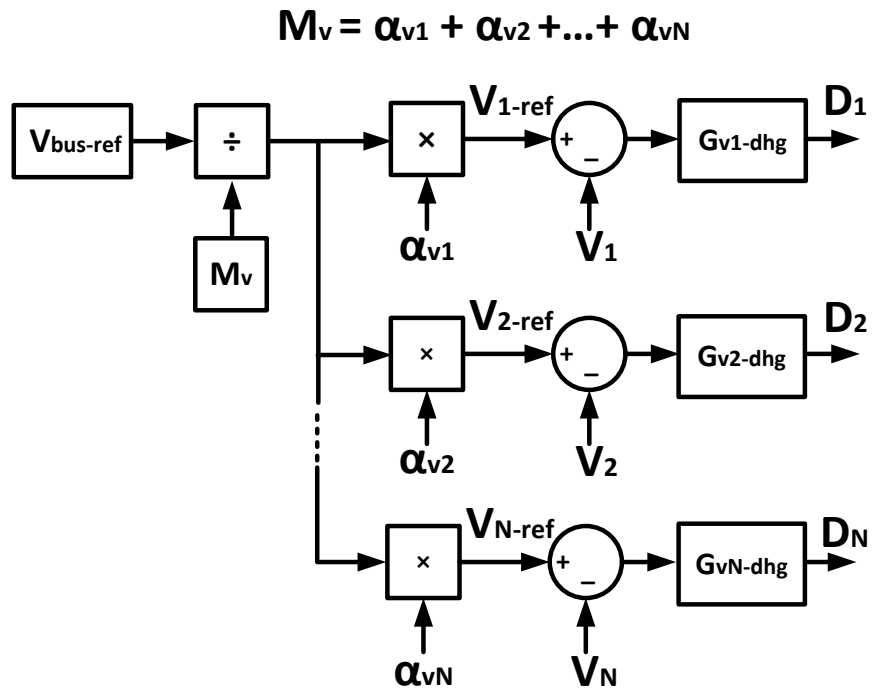

(a)

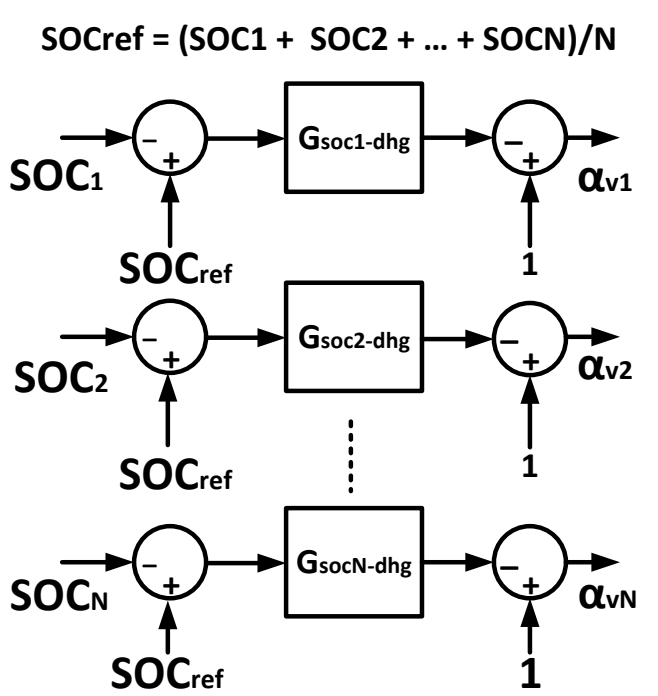

(b) 

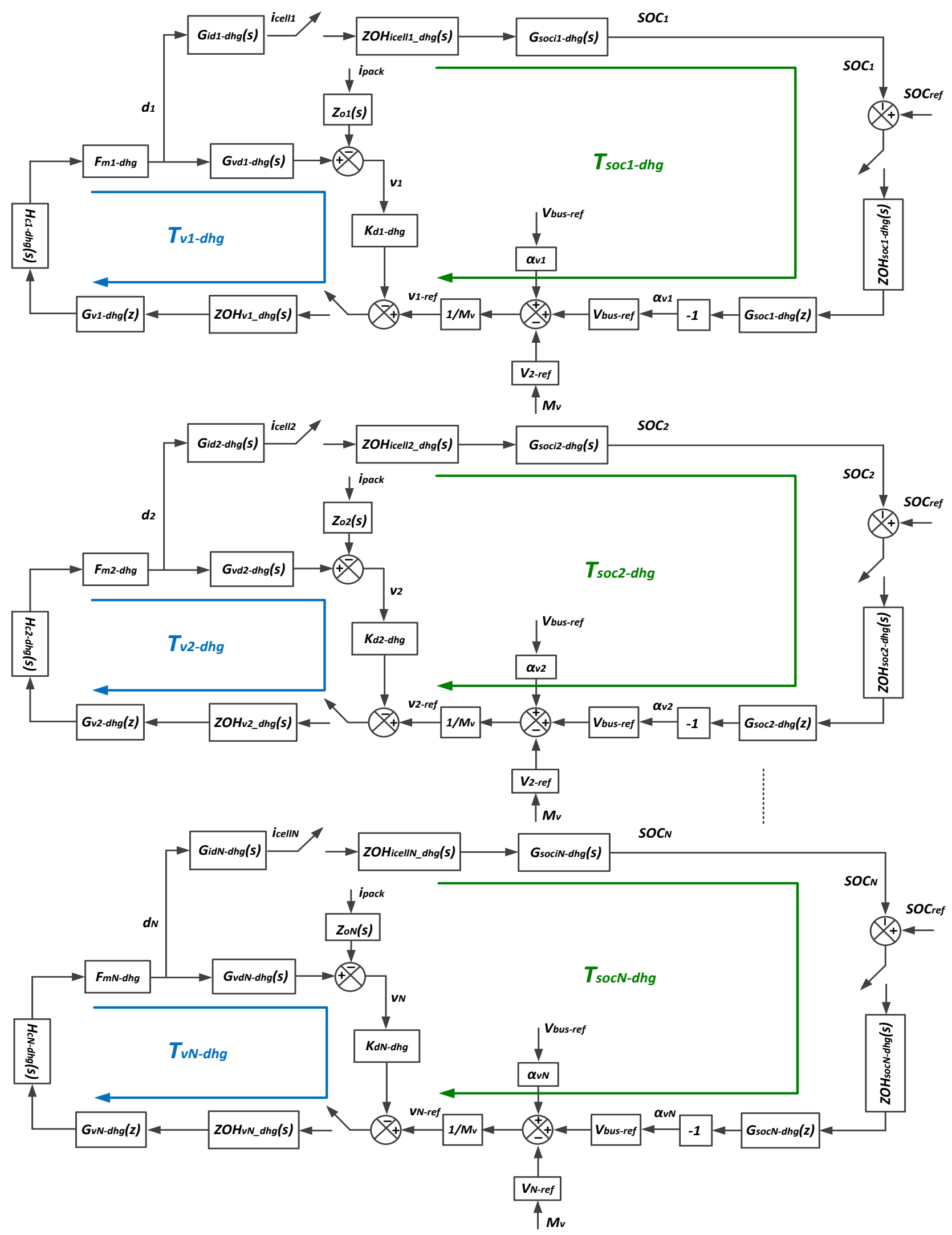
Figure 4
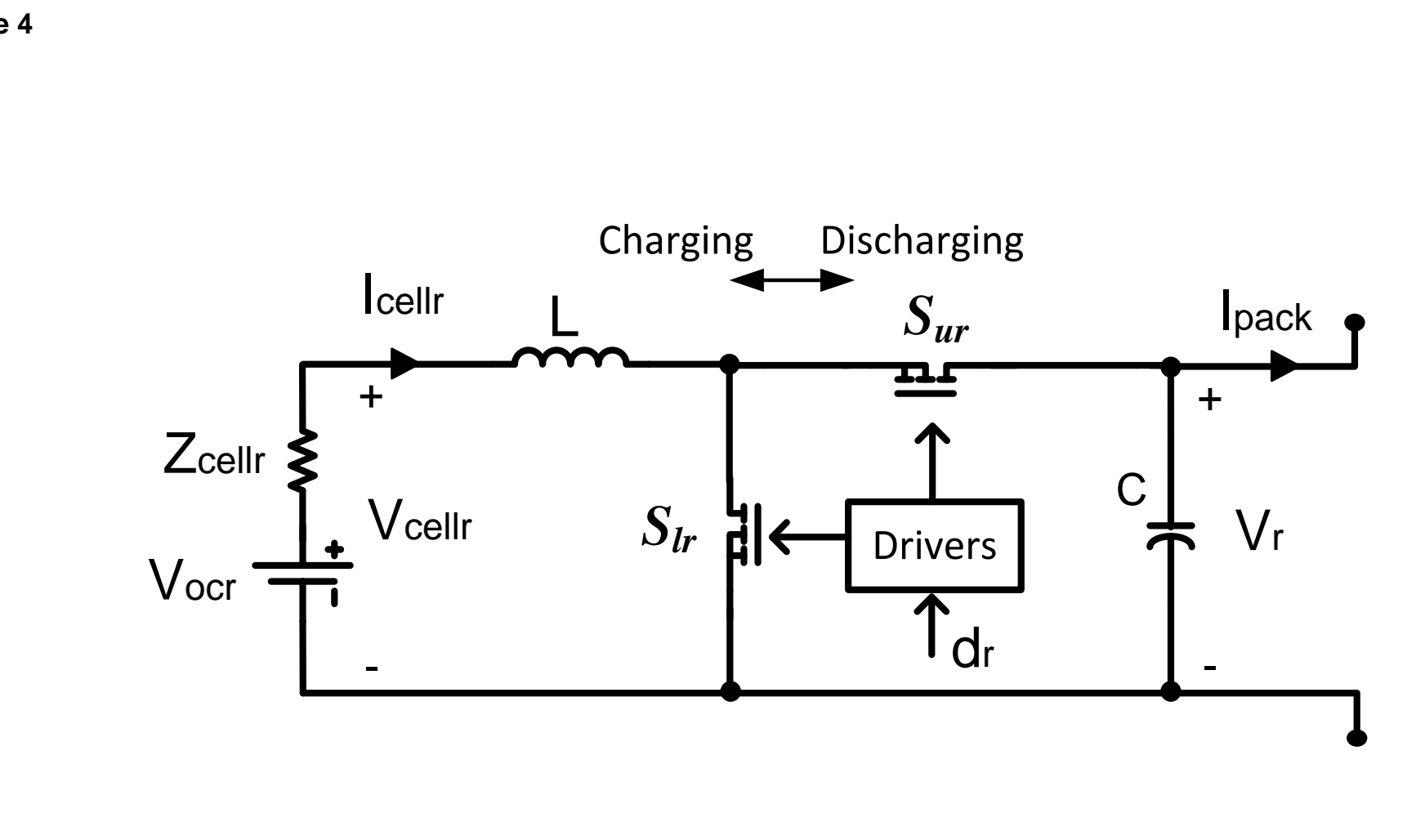

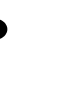
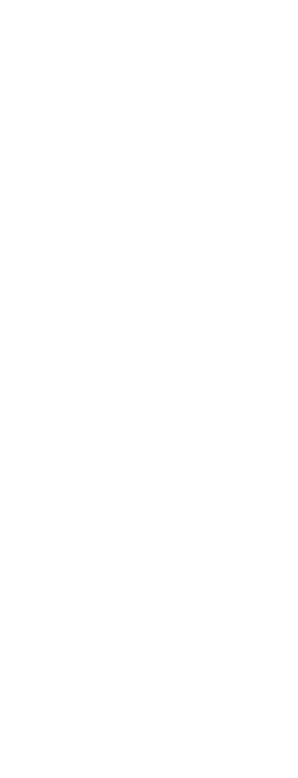


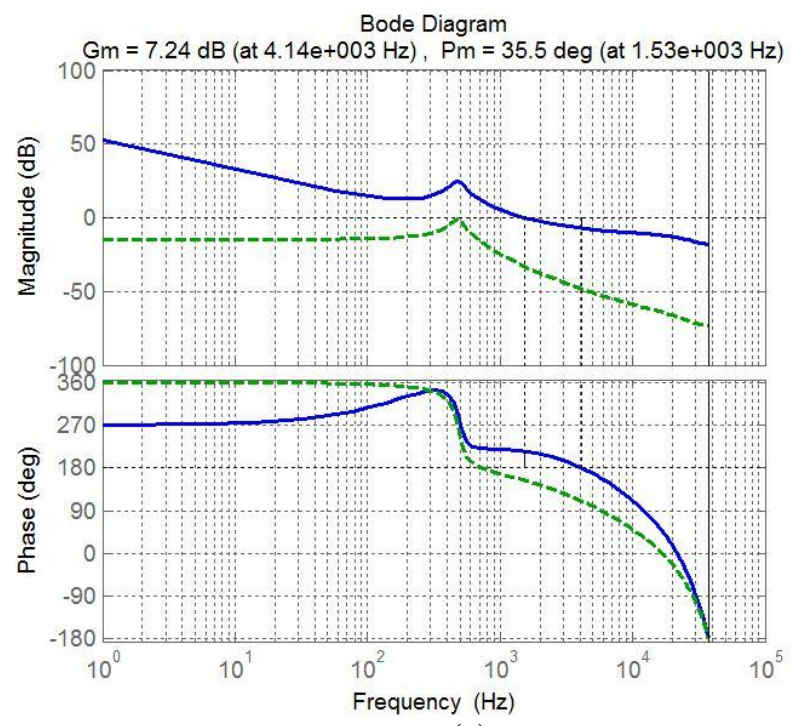

(a)

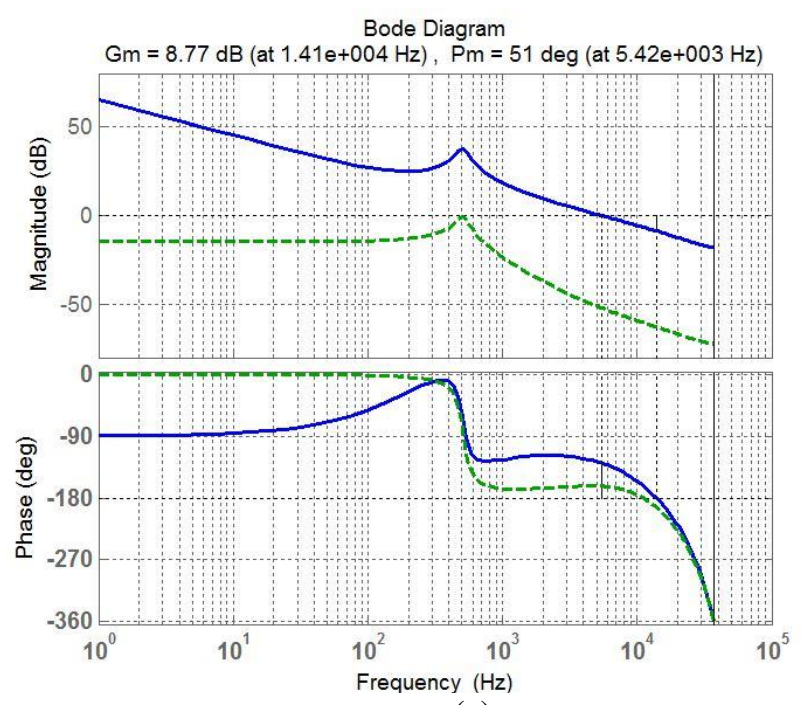

(c)

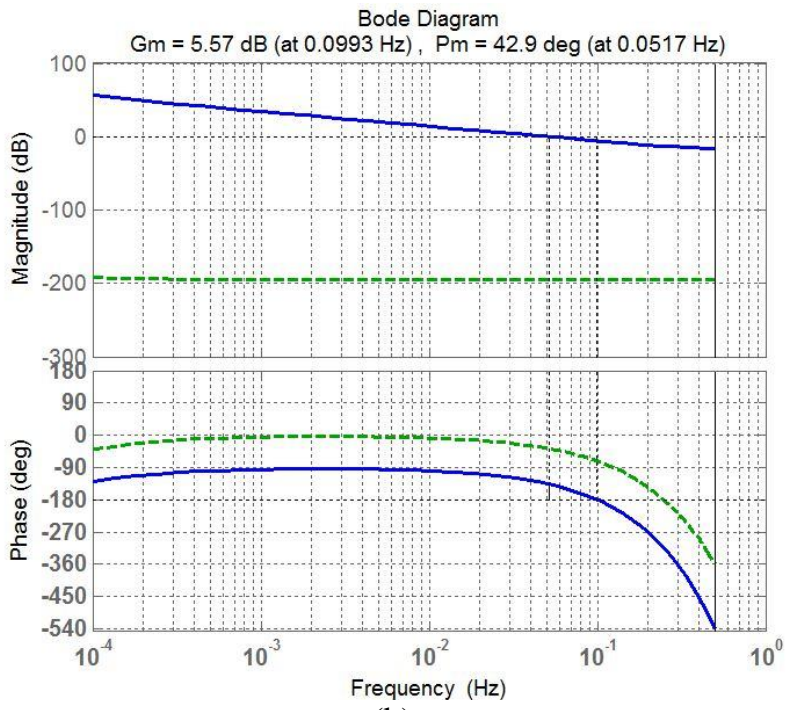

(b)

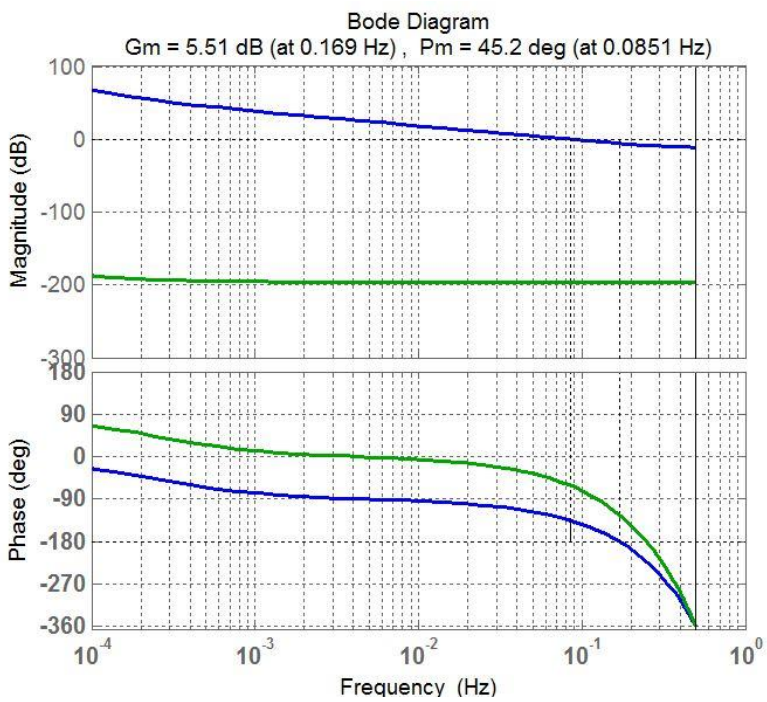

(d) 


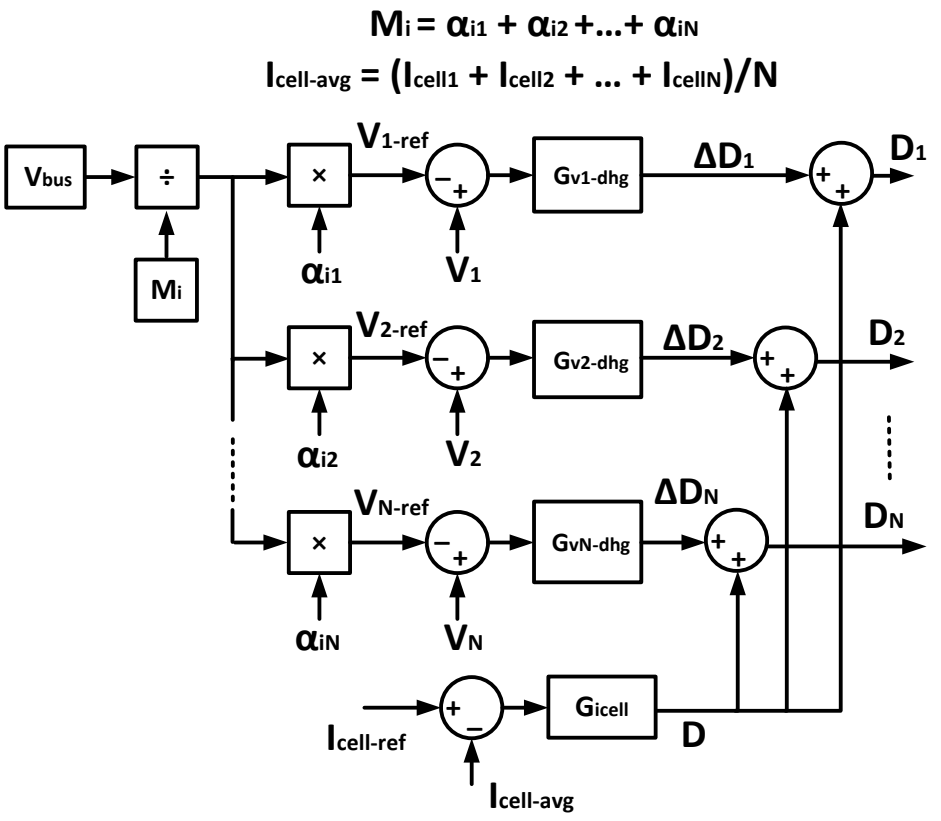

(a)

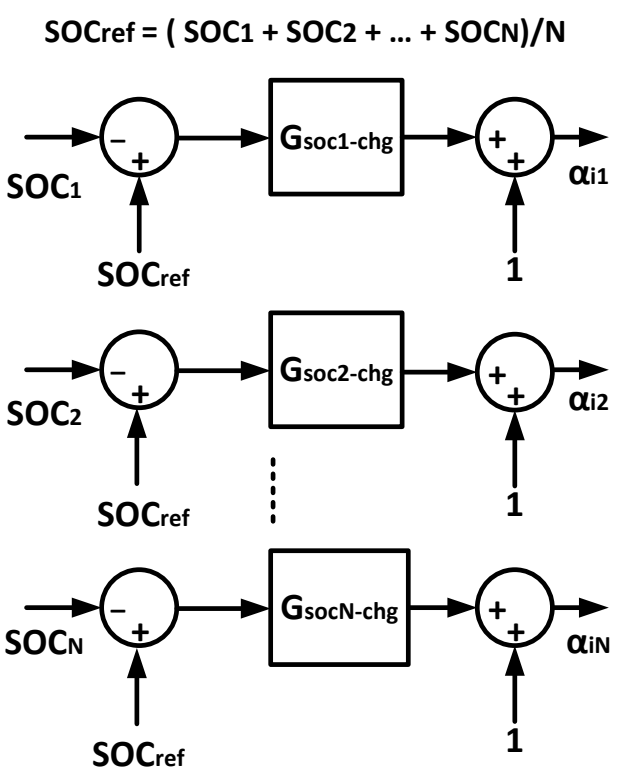

(b) 


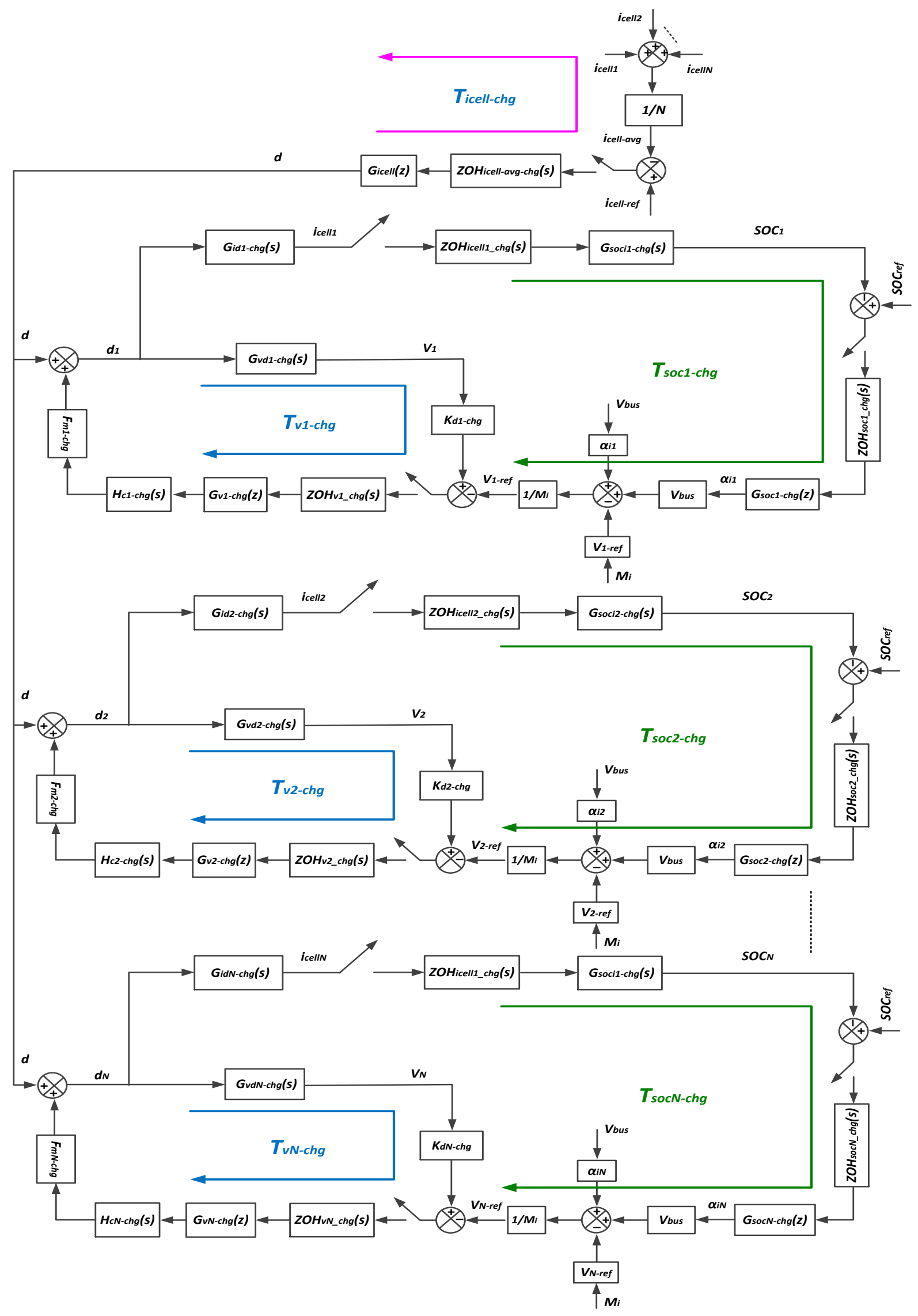




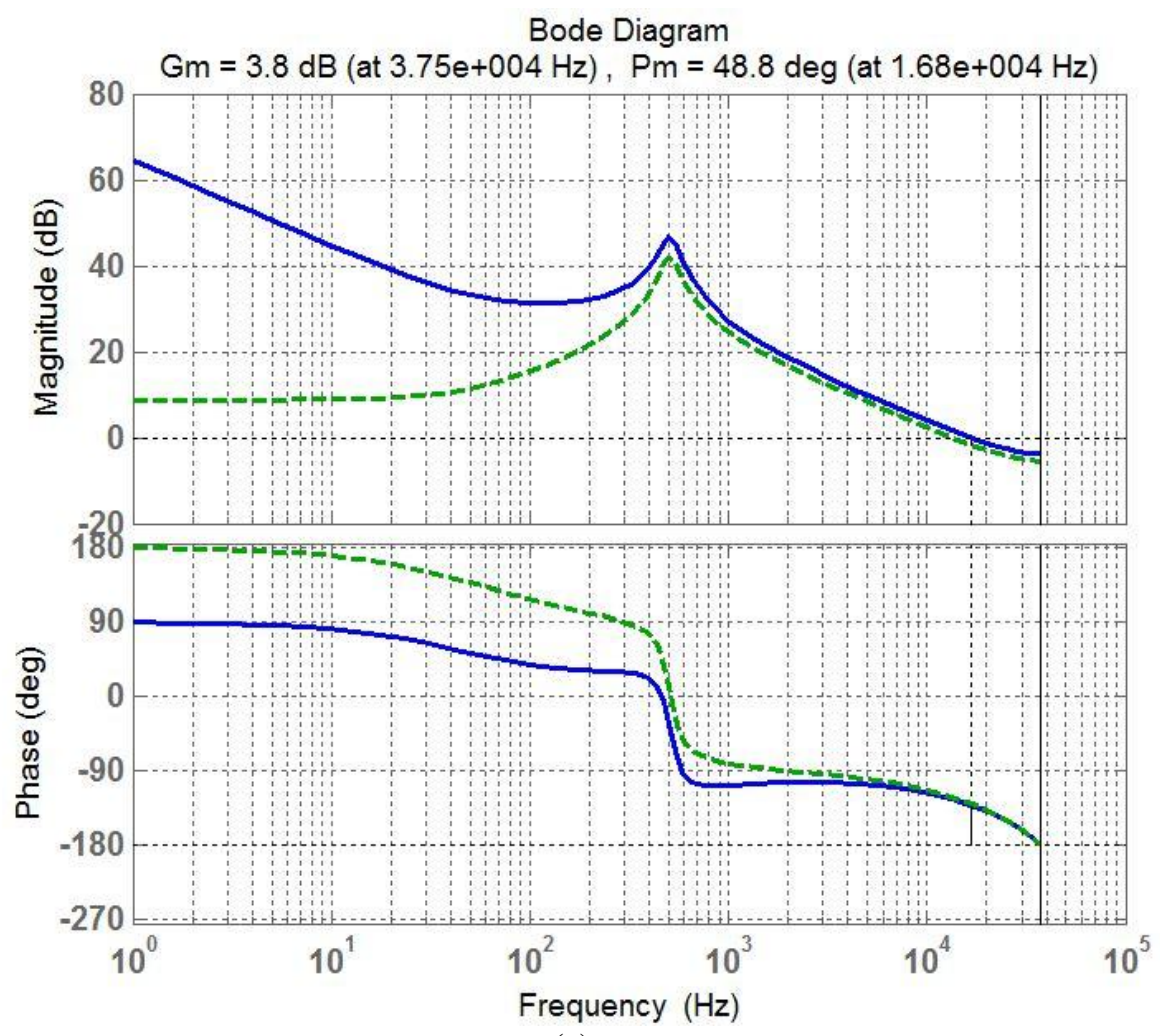

(a)

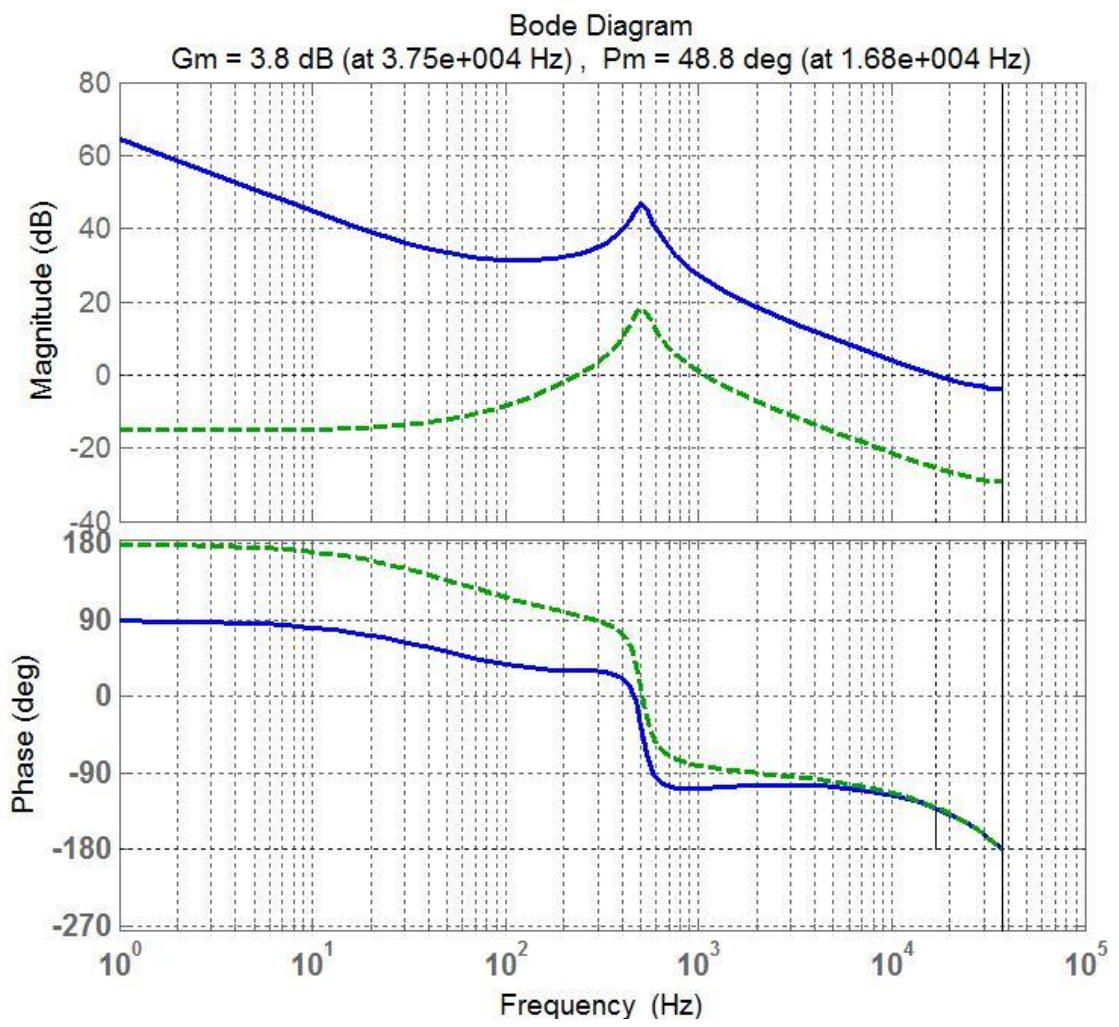

(b) 


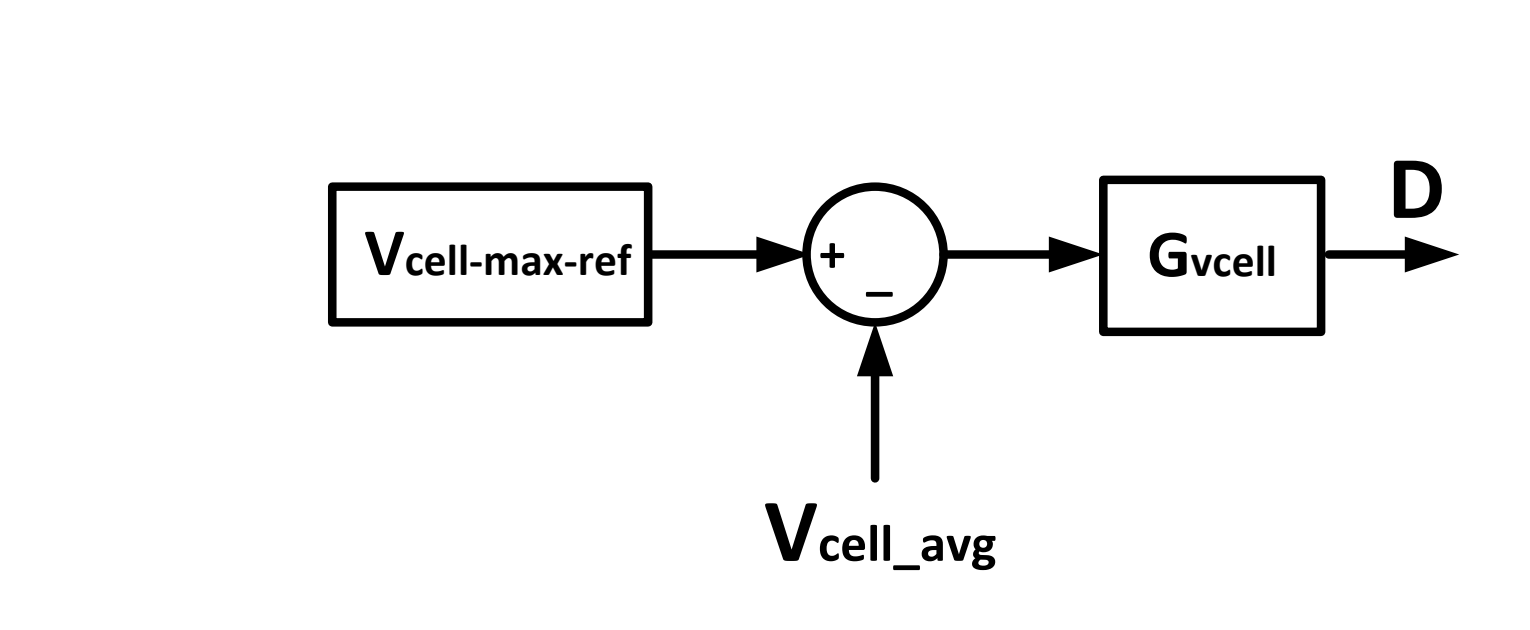

Figure 9

Figure 9

9

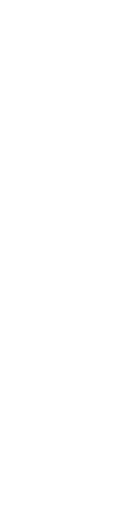
. 


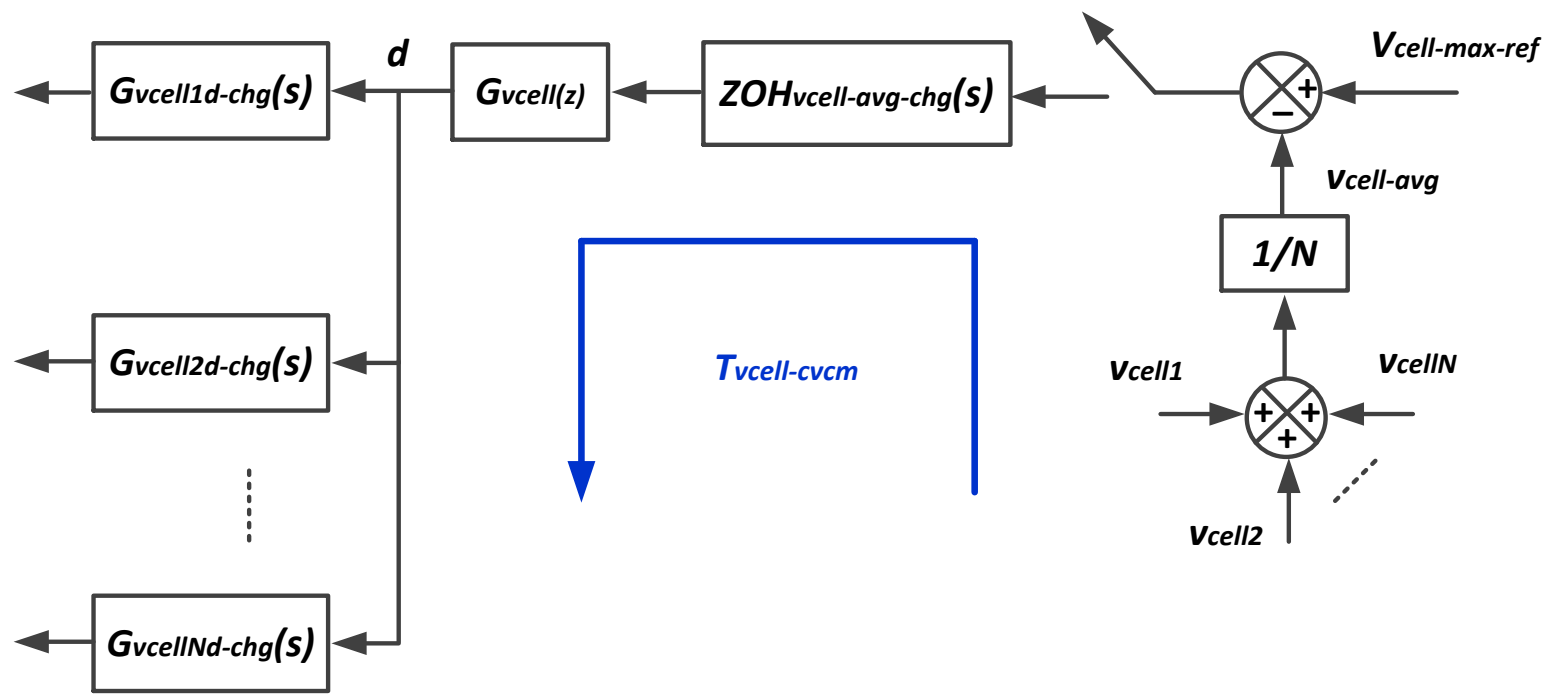




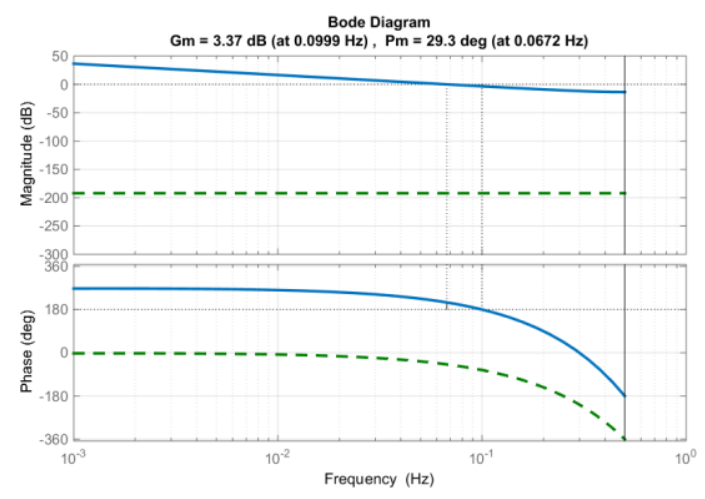

(a)

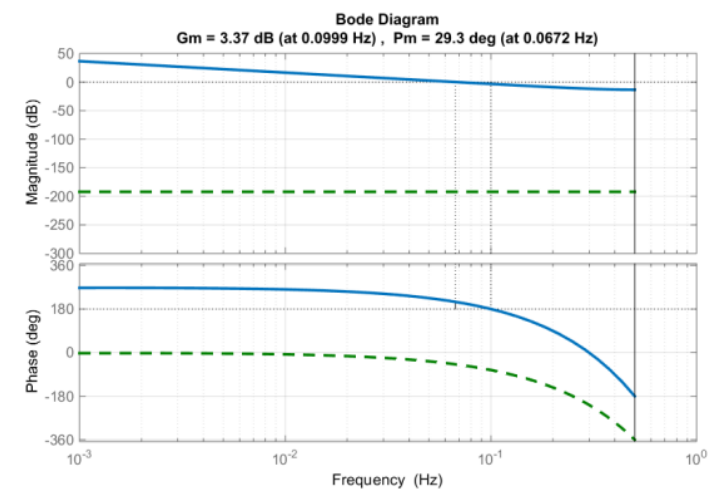

(c)

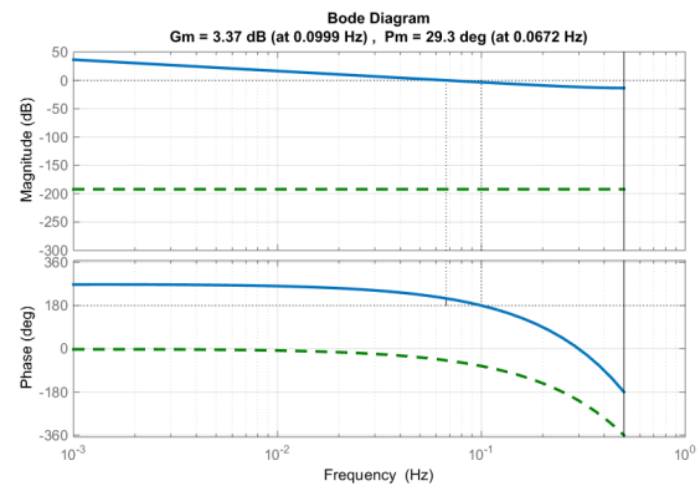

(e)



(b)



(d)

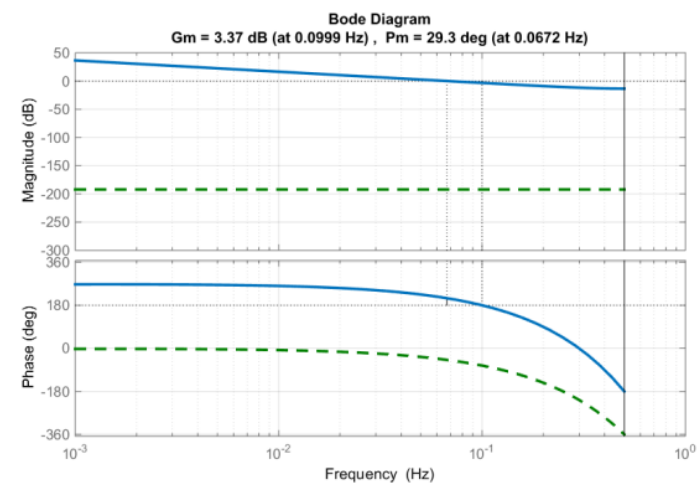

(f) 




(a)

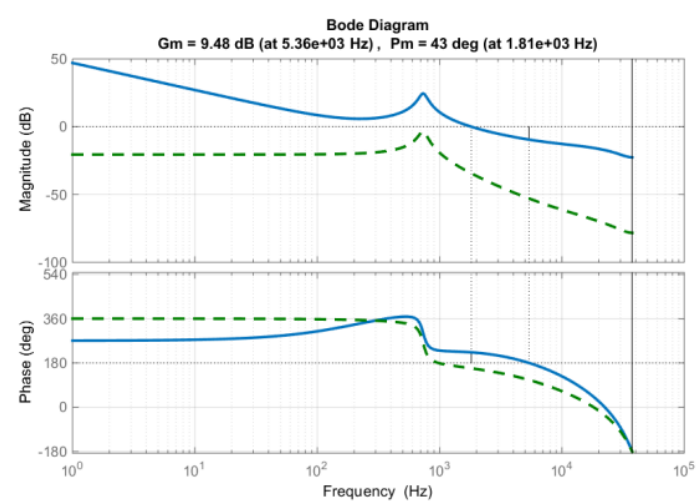

(c)

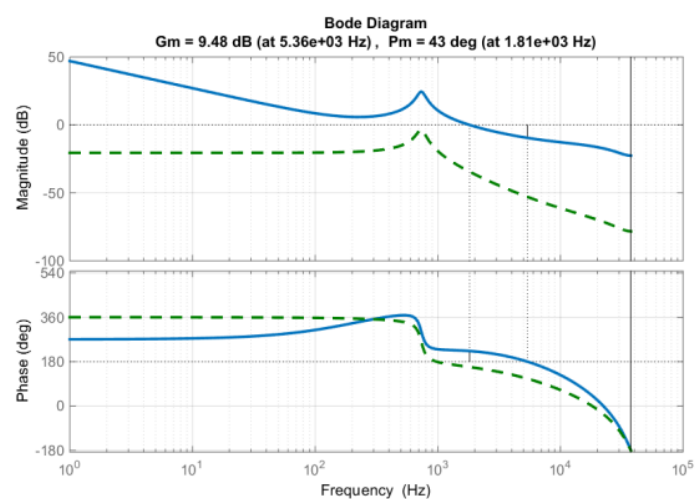

(e)

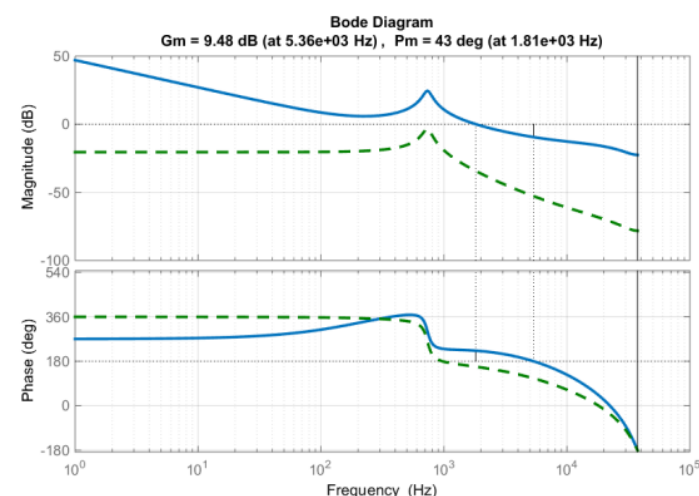

(b)

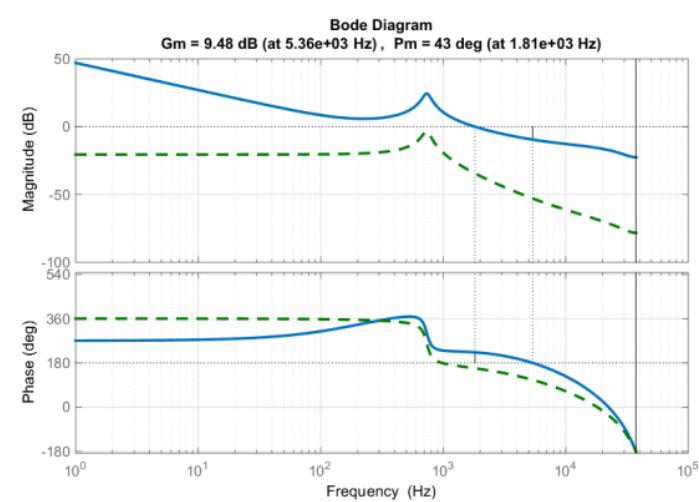

(d)

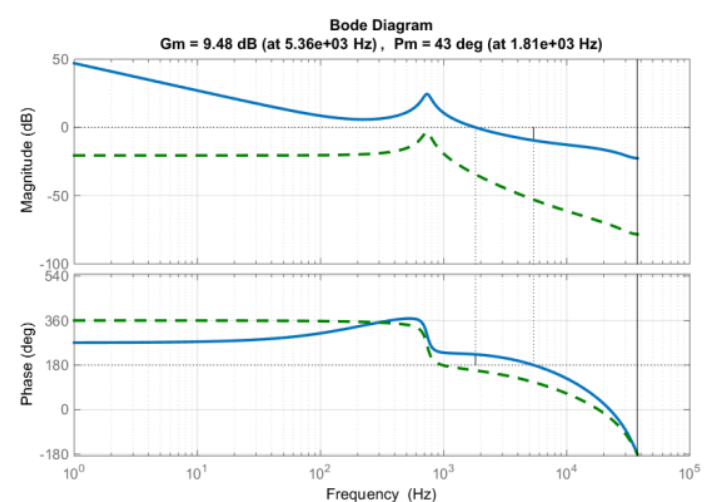

(f) 

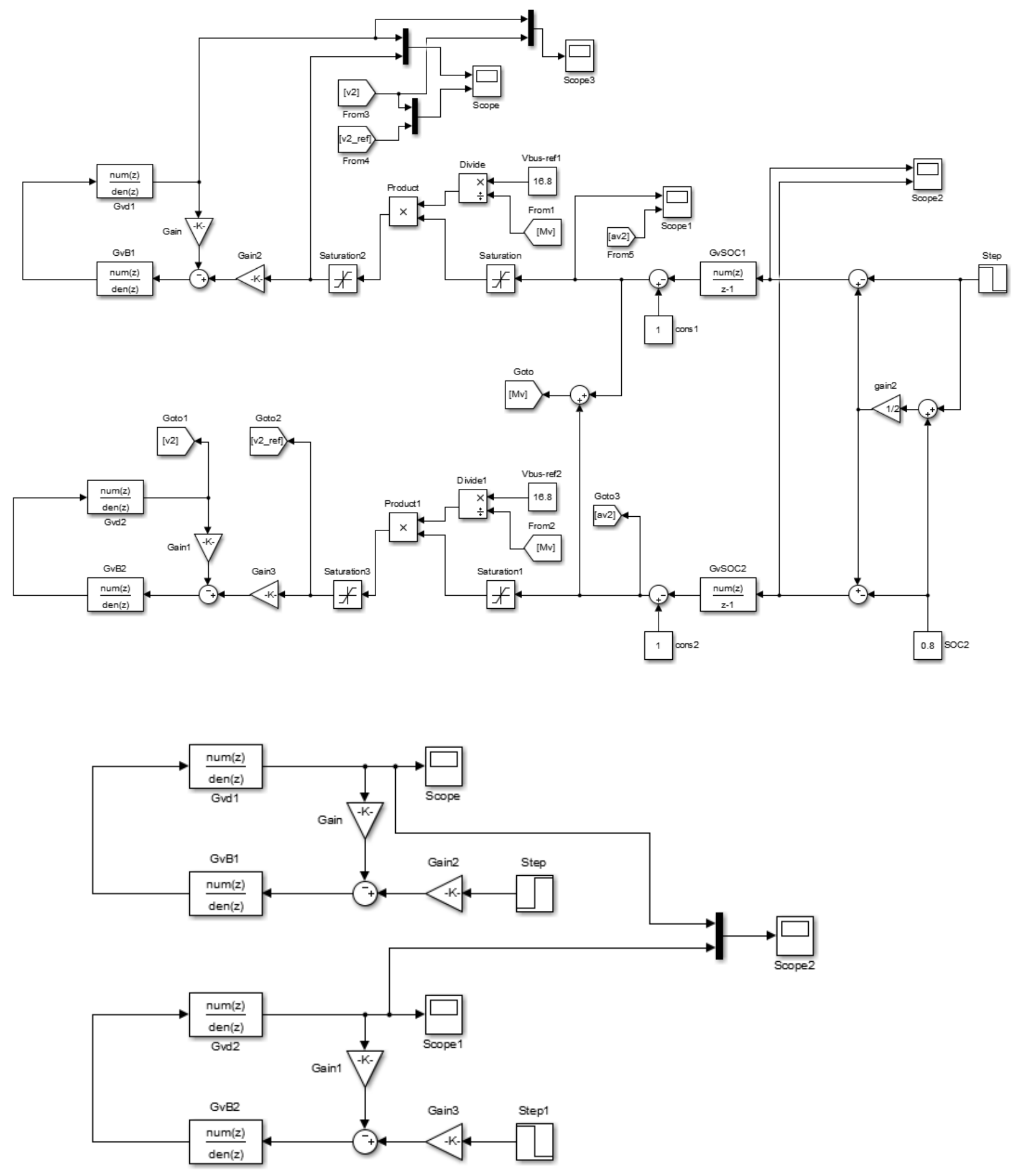


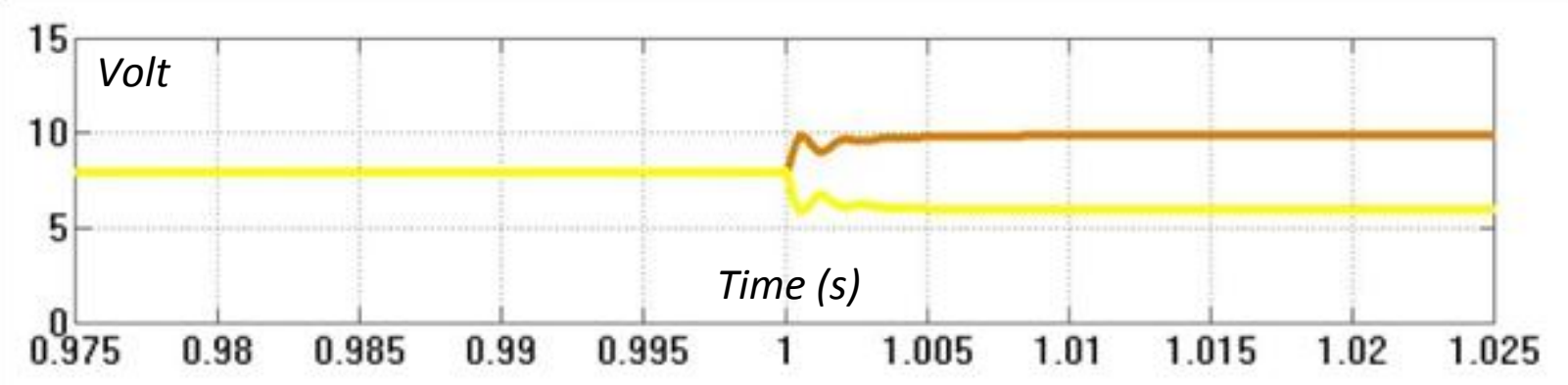

(a)

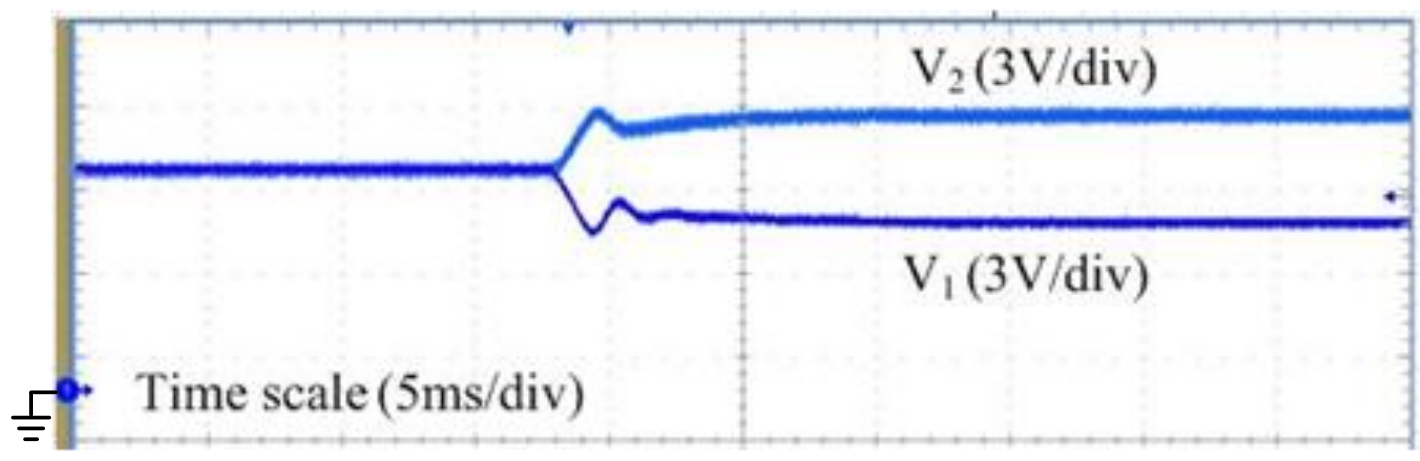

(b)



(c)

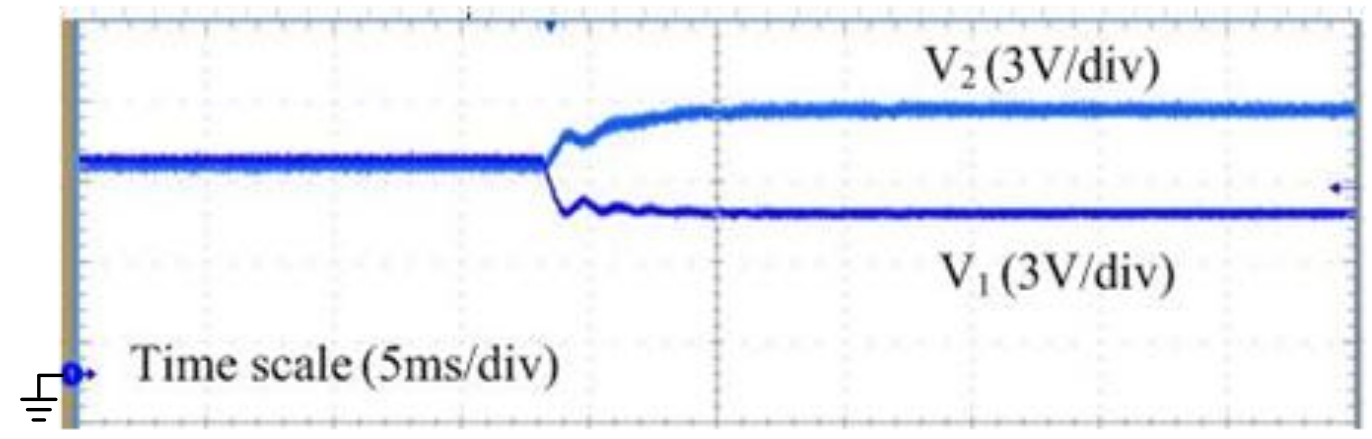

(d) 


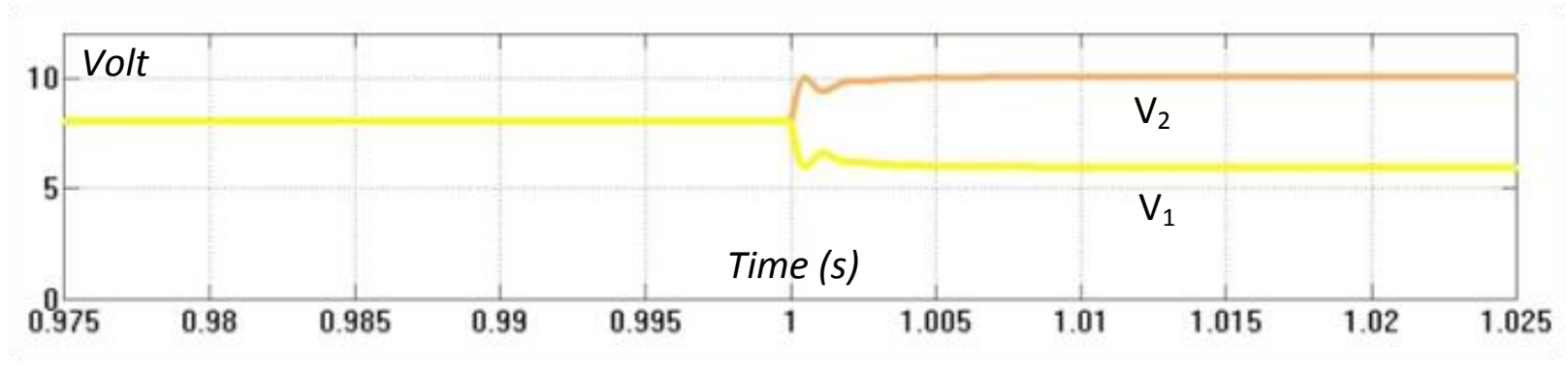

(a)

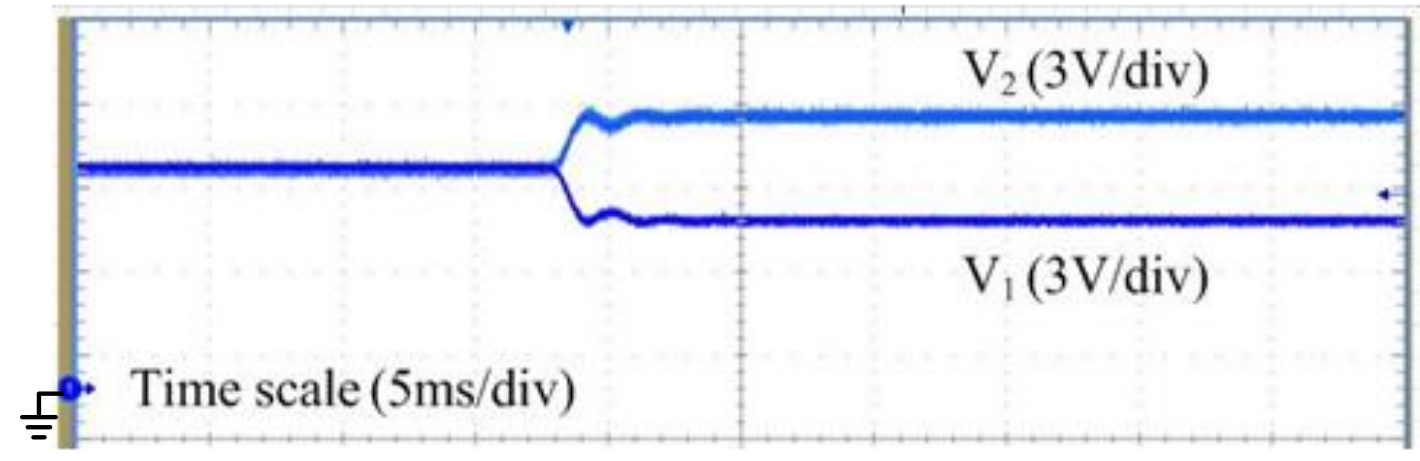

(b)

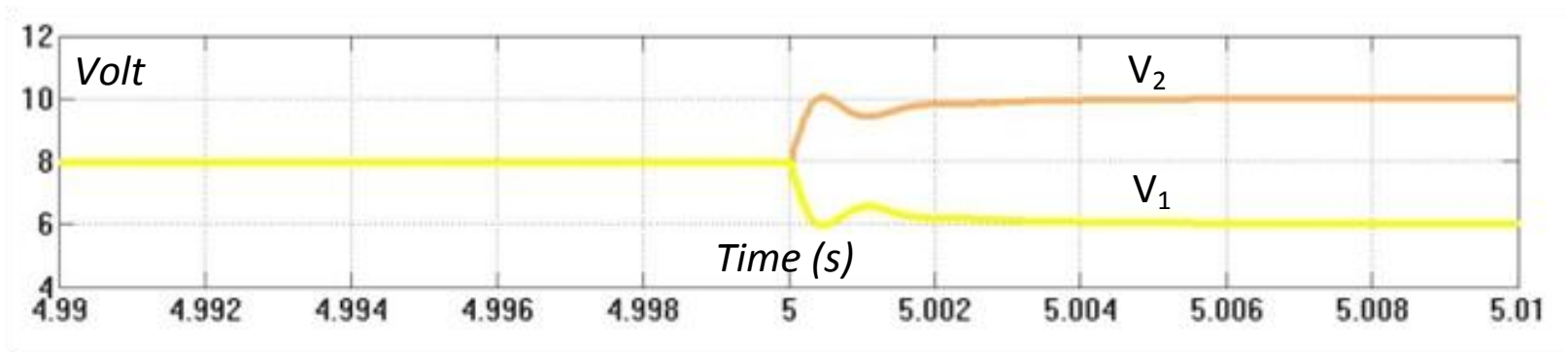

(c)

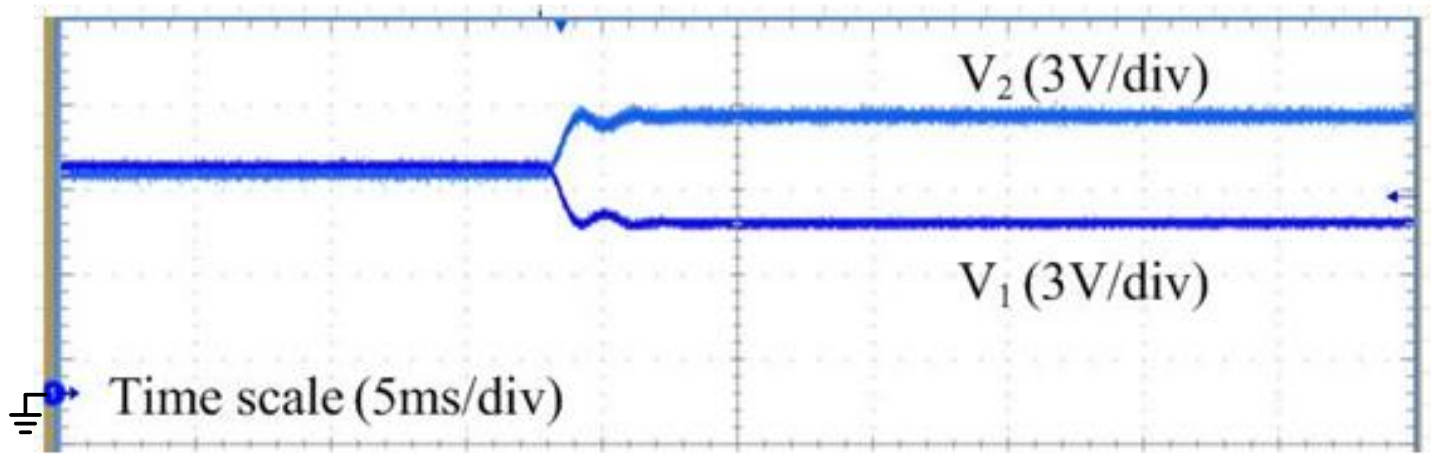

(d) 
Fig. 1. A simplified block diagram of (a) a conventional centralized battery system architecture and (b) distributed battery system architecture with energy sharing control [1].

Fig. 2. The energy sharing controller's basic block diagram during discharging operation: (a) the BPM output voltage control loop and (b) SOC balancing control loop.

Fig. 3. Small-signal model of the energy sharing controlled distributed battery system in discharge mode.

Fig. 4. Circuit diagram of a BPM.

Fig. 5. The bode plot of the uncompensated (dashed curve) and compensated (solid curve) for (a) BPM output voltage loop gain in discharge mode; (b) SOC balancing loop gain in discharge mode; (c) BPM input voltage loop gain in CCCM; (d) SOC balancing loop gain in CCCM.

Fig. 6. Energy sharing controller's basic block diagram during CCCM operation: (a) the BPM input voltage control loop and average cell charging current control loop; (b) SOC balancing control loop [1].

Fig. 7. Small-signal model of the energy-sharing controlled distributed battery system in constant current charging mode.

Fig. 8. The bode plot of uncompensated (dashed curve) and compensated (solid curve) for (a) Average cell current control loop gain in CCCM; (b) Average cell voltage control loop gain in CVCM.

Fig. 9. The energy sharing controller's basic block diagram during CVCM operation.

Fig. 10. Small-signal model of the energy-sharing controlled distributed battery system in CVCM.

Fig. 11. The bode plot of the uncompensated (dashed curve) and compensated (solid curve) for (a) BPM output voltage loop gain in discharge mode; (b) SOC balancing loop gain in discharge mode; (c) BPM input voltage loop gain in CCCM; (d) SOC balancing loop gain in CCCM; (e) Average cell current control loop gain in CCCM; (f) Average cell voltage control loop gain in $\mathrm{CVCM}$; All at extreme operating point $\mathrm{V}$ cell $=3 \mathrm{~V}$ and $\mathrm{Vo}=10 \mathrm{~V}$.

Fig. 12. The bode plot of the uncompensated (dashed curve) and compensated (solid curve) for (a) BPM output voltage loop gain in discharge mode; (b) SOC balancing loop gain in discharge mode; (c) BPM input voltage loop gain in CCCM; (d) SOC balancing loop gain in CCCM; (e) Average cell current control loop gain in CCCM; (f) Average cell voltage control loop gain in CVCM; All at extreme operating point $\mathrm{Vcell}=4.2 \mathrm{~V}$ and $\mathrm{Vo}=6 \mathrm{~V}$. 
Fig. 13. The mathematical simulation model of the distributed battery system.

Fig. 14. (a) Simulation model waveforms (top trace: V2; bottom trace: V1; horizontal axis unit: second; vertical axis unit: volt) ; (b) experimental waveforms for the BPM output voltages when V1-ref is changed from $8 \mathrm{~V}$ to $6 \mathrm{~V}$ while $\mathrm{V} 2$-ref is changed from $8 \mathrm{~V}$ to $10 \mathrm{~V}$ in discharge mode; (c) simulation model waveforms and (d) experimental waveforms for the BPM output voltages when SOC1 is suddenly changed from $80 \%$ to $75 \%$ under cell balanced condition where SOC1 $=\mathrm{SOC} 2=80 \%$ in discharge mode.

Fig. 15. (a) Simulation model waveforms (top trace: V2; bottom trace: V1; horizontal axis unit: second; vertical axis unit: volt) and (b) experimental waveforms for the BPM output voltages when V1-ref is changed from $8 \mathrm{~V}$ to $6 \mathrm{~V}$ while V2-ref is changed from $8 \mathrm{~V}$ to $10 \mathrm{~V}$ in charge mode. (c) Simulation model waveforms and (d) experimental waveforms for the BPM output voltages when SOC1 is suddenly changed from $80 \%$ to $85 \%$ under cell balanced condition where SOC1 $=\mathrm{SOC} 2=80 \%$ in charge mode. 